Review

\title{
Sustainability and the Fixed Bed Nuclear Reactor (FBNR)
}

\section{Farhang Sefidvash}

FBNR Technology LLC; Av. Carlos Gomes 257/602, Porto Alegre, 90480-003, Brazil;

E-Mail: fbnr.reactor@gmail.com; farhang@sefidvash.net; Tel.: +55-51-32091938

Received: 16 June 2012; in revised form: 16 July 2012 / Accepted: 18 July 2012 /

Published: 6 August 2012

\begin{abstract}
Sustainability as a multifaceted and holistic concept is analyzed. Sustainability involves human relationship with elements such as natural environment, economy, power, governance, education and technology with the ultimate purpose of carrying forward an ever-advancing civilization. The Fixed Bed Nuclear Reactor (FBNR) is an innovative, small, simple in design, inherently safe, non-proliferating, and environmentally friendly concept that its deployment can generate energy in a sustainable manner contributing to the prosperity of humanity. The development of FBNR will provide electricity as well as desalinated water through a simple but advanced technology for the developing, as well as developed countries. FBNR is environmentally friendly due to its inherent safety and the convenience of using its spent fuel as the source of radiation for irradiation purposes in agriculture, industry, and medicine. Politically, if a ping pong game brought peace between China and USA, a program of development of FBNR supported by the peace loving international community can become a more mature means to bring peace among certain apparently hostile nations who crave sustainable energy, desalinated water and simple advanced technology.
\end{abstract}

Keywords: inherent safety; water desalination; economic system; environment; human nature; education; technology; organic development; IAEA INPRO; innovative nuclear reactor

\section{Introduction}

The rapidly growing world population desiring an ever increasing standard of living while living on Earth with limited natural resources and having environmental limitations, make the subject of sustainability of utmost importance. The growing process of globalization, which came about due to 
the advancement of technologies of communication and transport, has created a total interdependency among all the nations of the world in all aspects being economic, cultural or otherwise. Before the advent of the industrial revolution and the process of mass production, the production to supply consumer goods to the peoples was the essential basis of the economic systems. In those conditions even slavery was justified to supply the necessary goods to the populations. The importance of production was so great that even the founders of the old religions while teaching love and compassion could not and did not forbid slavery as higher production was necessary to supply the basic needs of the populations. However, in the present world situation the excess of production and consumerism have become a threat to the Earth's natural resources and the environment. Therefore, it is important to obtain a deep understanding of sustainability that involves the nature of human beings and their conformity with the natural environment. This will enable us to adopt an adequate system of governance to avoid bringing misery to future generations, but on the contrary, to build a society where we can secure for the future generations the conditions that can guarantee them true prosperity.

\section{World Summit on Sustainable Development}

The United Nations Conference on Sustainable Development, Rio+20, was planned to be attended by Heads of State and Government of 193 Member States, as well as other representatives [1]. The so-called "major groups"-non-governmental organizations, business groups, indigenous communities, local authorities, farmers' organizations, children and youth groups, women's organizations and the scientific and technological community - all having their spaces guaranteed, in order to represent civil society. The two central themes to Rio 20 were a green economy in the context of sustainable development and poverty eradication all within an institutional framework of sustainable development.

Some 130 heads of state and government, along with more than 50,000 representatives of international agencies, civil society, and other groups, attended the Conference, which has aimed to assess progress on sustainable development since the 1992 Rio Earth Summit. Two major themes-building a green economy and creating a better institutional framework-have been discussed in numerous forums. The concept of world-encompassing trusteeship was launched where the world leaders seeking to promote sustainable development should embrace the principle that each human being enters the world as a trust of the whole and, in turn, bears a measure of responsibility for the welfare of all. As long as one group of nations perceives its interests in opposition to another, progress will be limited and short-lived. Among the other areas discussed was the need for a principle-based approach to collective decision-making and the importance of addressing both extremes of the poverty-wealth spectrum [2].

\section{Sustainability}

Sustainable development implies ensuring that it meets the needs of the present generation of human beings without compromising the ability of future generations to meet their own needs. It contains within it the key concept of "need" and not "desire", as desire has no limits and satisfying it is devastating. It is impossible to satisfy desires in the world where natural resources are limited and production necessarily brings about pollution. Sustainable development is not simply about protecting the environment, but it is about effectively tackling interconnected challenges related to both human 
and environmental survival. Humanity is an organically integrated whole governed by relations of interconnection, mutuality and balance. The well-being of each part is inseparable from the well-being of the whole. Sustainability is a multifaceted concept. It involves our relationship with elements such as the natural environment, human nature, knowledge, power, governance, economics, equality, education and technology. The purpose of human beings on Earth is to carry forward an ever-advancing civilization in a sustainable manner.

At the Rio+20 Conference, the following was defined: Environment, society, and economy are the three dimensions of sustainable development. The key to sustainable development is change of paradigm. The basis of a sustainable society is not too much and not too little, but moderation in all things.

\section{Environment}

Humanity must consider itself the trustees, or stewards of the planet's vast resources and its biological diversity. We must learn to make use of the earth's natural resources, both renewable and non-renewable, in a manner that ensures sustainability and equity into the distant future. This attitude of stewardship will require full consideration of the potential environmental consequences of all development activities. It will compel humanity to temper its actions with moderation and humility, realizing that the true value of nature cannot be expressed only in economic terms. It will also require a deep understanding of the natural world and its role in humanity's collective development. Therefore, sustainable environmental management must be seen as a fundamental responsibility that must be shouldered [3].

At the Rio+20 Conference, the following was elucidated: Water and environment do not belong only to humankind, but to allbeings on Earth. We all are born with the right to breathe air and drink water. Therefore, air and clean water are human rights. Water is not property. Nature has its own values. Nature has the right to stay clean. If we allow micro control of water resources, then it will lead to the macro control of rivers and the seas. Availability and management are two dimensions of water.

\section{Human Nature}

A model of human nature and functioning sees man as the product of two basic conditions, the physical (material) and the spiritual (non-material). The physical dimension of man's existence derives from his genetic endowment, determined at conception, plus the interaction of this configuration with the environment. This interaction produces an internal, physical milieu, which is unique to each individual, though sharing common features with all members of the human species. The spiritual dimension of man's nature derives from the existence of a non-material entity, the soul, which is individualized at the moment of conception. Just as the physical body of man has various physical capacities, so the soul has its capacities, called spiritual capacities of man. Among the most important spiritual capacities of man are those of the intellect or understanding, the heart or feeling capacity, and the volition or will. The interactions of the individual with his environment affect not only his body but his soul as well. They develop both the genetically given physical capacities and the initially given spiritual capacities. These interactions may be called learning or education, and they give rise to a third aspect of man's total character, an aspect that is both physical and spiritual. In sum, there are three 
essential aspects of the character of man: his genetic endowment, which is surely physical; his soul and its capacities, which are purely spiritual; and education, which is both physical and spiritual. Human beings differ from animals by spiritual qualities that involve intellect, sentiment and volition. Intellect involves reasoning, memory, perception, and imagination. Sentiment involves love, intuition, compassion, and benevolence. Volition or will is the capacity to initiate and sustain an action [4].

\section{Power and Authority}

There are four types of power behind an authority: (1) force, such as military force that executes the orders; (2) negotiation, involves the exchange of favors; (3) integration, which uses logic and principles of human rights; and (4) love, that is hopefully to be the mechanism used in the future world society. In the world of existence there is indeed no greater power than the power of love. A prosperous society will come about only when its peoples and authorities will interconnect through love and respect and their actions are guided by higher spiritual values.

The power is with people who are at the bottom of the pyramid of society and who elect the members of their governing institutions. The authority is with the governing institutions. People must have confidence in their authorities that they are in the institutions to serve them. When these two are interconnected through love and respect, then the society will function effectively.

The educational process should place emphasis on moral values in order to create a society in which authority and power are harmoniously interconnected in the pyramid of society, from top to bottom and bottom to top, respectively. The authority in such a society will be achieved through love and respect of individuals to the institutions governing the society. Rigid rules of behavior and over centralization of authority belong to the age of humanity's childhood; similarly, unchecked freedom and unrelenting criticism are representative of the age of adolescence. New insights on power are required for the age of human maturity.

\section{Governance}

Governance is the sum of the many ways individuals and institutions - public and private - manage their affairs. It is a continuing process through which conflicting or diverse interests may be accommodated and cooperative action may be taken. Global governance involves non-governmental as well as governmental organizations, citizen's movements, multinational corporations and the global capital market. Interacting with these are global mass media [5].

The authority to direct the affairs of the world locally, nationally and internationally must be conferred on elected institutions. However, the power to accomplish the tasks of the community resides primarily in the mass of the public. The authority of the institutions is an irrevocable necessity for the progress of humanity; its exercise is an art to be mastered. The power of action in the individual must be unlocked at the level of individual initiative and surges at the level of collective volition. The elected authorities in such a society must have the highest moral values possible to be able to achieve such trust and love. Therefore, they cannot be elected through the present day process of election customary in the so-called democratic societies. Corruption is inherent to the present system of nomination and electoral campaign. The elected individual becomes "corrupted" even before starting 
his work as he no longer can act freely according to his conscience, but needs to act in favor of those who supported and paid for his/her electoral campaign.

At the Rio+20 Conference, the following was said: Never before has the world produced so much wealth, and the world never had such extreme poverty. The lack of jobs, especially for youth, is the cause of most of the problems such as violence, drugs, etc. We need to have a vision to put into action to abolish poverty. Poverty is related to human dignity, power, and requires good governance.

Governance involves the stages of maturity of the parties involved. Humanity as a whole can be exemplified as a single human being goes through three stages of childhood, adolescence, and maturity during its process of development. The stage of childhood is the stage of dependency seeking help. The stage of adolescence is the stage of seeking independency and thus the stage of rebelling. The stage of maturity seeks dialogue and going through processes of consultation to solve problems. Therefore, before reaching maturity, there is no hope for humanity to solve its problems and reach world unity.

\section{Economic System}

We must attain a proper understanding of the role of economics. Failure to place economics into the broader context of humanity's social and spiritual existence has led to a corrosive materialism in the world's more economically advantaged regions, and persistent conditions of deprivation among the masses of the world population. Economics should serve people's needs. The societies should not be expected to reformulate themselves to fit the economic models. The ultimate function of economic systems should be to equip the peoples and institutions of the world with the means to achieve the real purpose of development: that is, the cultivation of the limitless potentialities latent in human consciousness.

The purpose of a real economic system is to bring about the necessary physical and material means for individuals and the society to live in comfort, to be able to dedicate their lives to the activities of higher values and their spiritual progress. An economic system should provide the minimum necessary for the survival, health, and education of every human being thus eliminating the extremes of wealth and poverty.

Any economic system needs a stimulus to make the individuals work and provide the material and services needed by the others. In the present economic systems, this basis is production and consumption. In such a system, the production, not only the production of useful goods but even the superfluous items, need to be stimulated to keep the economic system functioning. The production of superfluous goods results in the exhaustion of the worlds' limited natural resources and increases pollution. Generally speaking, any item that is produced comes about from the combination of materials and energy, principally electric energy. Electricity production is inherently a pollution producing process. Therefore, production of anything involves increase of pollution besides the reduction of the Earth's natural resources.

The future economic system needs an adequate basis for stimulation through which people are motivated to work. The materialistic basis of production may be replaced by the spiritual basis of service and cooperation; thereby, educating people that work performed in the spirit of service to humanity is of highest merit in the society, and it is equivalent to the act of worship in religious terms. Education for such a mind-set, in a relatively short time, will bring about people who will produce products and services of highest quality and the best utility, with minimum waste and environmental impact. 
The advance of civilization depends on the dedication of individuals to work. In the present capitalist society, the "desire" to consume goods and services, motivates the majority to work. This "desire" may correspond to the "need" of the individuals or not. The desire to serve encourages people to work exceptionally well, beyond their minimum needs, helping society grow in a sustainable manner. If only "desire for superfluous consumption" turned into "contentment" and no other motivation of higher values takes its place, there is a danger of bringing stagnation to the advancement of the society.

The real economy is the result of a sustainable production and consumption process stimulated by the higher principles of a value system such as service and cooperation. This requires re-education and transformation of individuals through the development of human's spiritual qualities. We need to embark on building a new world economic system in such a manner to bring about prosperity for humanity. Prosperity of humanity means satisfying the material and spiritual needs of humanity which should become the goal of any economic system.

\section{The Concept of Green Economy}

The UN Environment Program defines the Green Economy as one that results in improved human well-being and social equity, while significantly reducing environmental risks and ecological scarcities. In its simplest expression, a green economy can be thought of as one which is low carbon, resource efficient and socially inclusive. The green economy within the concept of sustainable development and elimination of extreme richness and poverty would ultimately entail a radical and complete transformation of human civilization.

Sustainable production is not simply about 'greener' technology but rather, should involve systems that enable all human beings to contribute to the productive process. In such a system, all are producers, and all have the opportunity to earn (or receive, if unable to earn) enough to meet their needs. More than simply the means of generating wealth and meeting basic needs, work provides a role in the community and developing one's talents, refining one's character, rendering service and contributing to the advancement of society.

At the Rio+20 Conference, the following was said: Green economy requires payment for environmental questions. Green economy puts monetary value on the environment. This adds further distance to nature. This serves economic gain, and not human well-being. The financial market should work towards the direction of a real productive economy. The new textbook on economy should say that there is no economy without environment and for the sake of sustainable development emphasis on the word "growth" should be substituted with "environment".

\section{Prosperity}

There are various concepts of prosperity: (1) Prosperity as wealth. Even though wealth is a necessary condition for prosperity, it is not a sufficient condition in itself. Otherwise, there would not be any unhappy rich people or happy poor people; (2) Prosperity as the ability to satisfy any immediate desire. This cannot be real prosperity, as we know many immediate pleasures must be sacrificed for future gains; (3) Real prosperity involves the satisfaction of all the physical and spiritual needs of the individual. Therefore, true prosperity may be defined as the holistic fulfillment of all physical and spiritual needs of a human being. The spiritual needs are related to the intellect, sentiment, and 
volition. Thus wealth and economic growth are necessary but not sufficient conditions for prosperity. The future economic system and its activities should bring about, in a sustainable manner, material as well as intellectual and emotional growth, empowering people into action by their free will to the service of humanity, and thereby helping the progress of an ever-advancing civilization.

\section{Education}

To implement any vision of a society, it is only possible through education, in particular moral education. Education differs from instruction in that it forms the individual and brings about transformation. The children and youth of today are the citizens and administrators of the future society. Parents, schools, and mass media are educators and builders of the future society. A value system based on equality and unity of humanity needs to be taught. The concept of unity of mankind implies the necessity of cooperation amongst individuals and service to humanity. That is why the establishment of unity of humankind is the basis to the construction of a sustainable future society. Unity is not uniformity, but it is a dynamic process of unification of diverse peoples in a common understanding, thus bringing about unity in diversity. This consciousness will transform the behavior of the future society. In today's understanding of our economic system, for example, we produce things in a manner to gain maximum profit, but we should be motivated to produce items with maximum benefit to the consumers, thus having highest quality to last longer, and have multipurpose functions. This attitude will result in consuming less material and energy resources for production.

The moral values need to be implemented in society through the process of education that will bring about the transformation of the individuals. This process is sometimes called spiritualization. The concept of spirituality according to William Hatcher is the process of a full, adequate, appropriate and harmonic development of the human beings spiritual capacities, such as intellect (reasoning, memory, perception, and imagination), sentiment (love, intuition, compassion) and volition (free will-the ability to start an action and give continuity to it). This process will bring about the future golden society made of noble individuals who will be engaged in the growing process of higher intellect, more noble sentiment and motivated to work to contribute to an ever advancing civilization [4].

At the Rio+20 Conference, the following was said: Education is at the foundation of everything. Transformation comes about through education. Educate the future leaders of the world who are the children and youth of today. If we do not leave a better world for the future, let us leave better children for the world of the future. We should concentrate on educating the people and not the governments, because people change the world and not the governments.

\section{Technology}

The majority of technological development is driven by market forces that do not reflect the basic needs of the world's people. Furthermore, the emphasis on the transfer of technology without accompanying efforts to increase participation in the generation and application of knowledge can only serve to widen the gap between the rich and the poor; i.e., between the 'developers' and the 'users' of technology. The establishment of centers for research and training constitutes a major challenge to sustainable development. If successfully met, however, the result will be to break the present unbalanced flow of knowledge in the world and dissociate development from ill-conceived present processes. 
The process of harnessing and deploying technical innovation takes time. This is why organizational capacity-building must be a central component of development practice. Apart from individuals acquiring skills, there has to be a learning process where local centers of technology are not only absorbing knowledge, but are also generating knowledge [3].

\section{Energy}

The increase in world population and its desire for a higher standard of living requires an ever increasing energy production, especially electricity. None of the forms of energy alone is a panacea. The solution to the energy problem is in the utilization of all forms of energy available. Alternative forms of energy are insufficient to supply the world energy demand, but nuclear energy can be produced with abundance. Generation of nuclear energy does not contribute to the effect of global warming. Generation of nuclear energy by the future innovative reactors will be fully safe, environmentally friendly and acceptable to the general public.

About $30 \%$ of the world's primary energy consumption is used for electricity generation, about $15 \%$ is used for transportation, and the remaining $55 \%$ is converted into hot water, steam and heat. Non-electric applications include desalination, hot water for district heating, and heat energy for petroleum refining, for the petrochemical industry, and for the conversion of hard coal or lignite. For non-electric applications, the specific temperature requirements vary greatly. Hot water for district heating and heat for seawater desalination require temperatures in the 80 to $200{ }^{\circ} \mathrm{C}$ range, temperatures in the 250 to $550{ }^{\circ} \mathrm{C}$ range are required for petroleum refining processes. Water-cooled reactors can provide heat up to about $300{ }^{\circ} \mathrm{C}[6]$.

At the global level, the energy system — supply, transformation, delivery and use - is the dominant contributor to climate change, representing around 60 per cent of total current greenhouse gas (GHG) emissions. Current patterns of energy production and consumption are unsustainable and threaten the environment on both local and global scales. We need to address the dual challenges of meeting the world's energy needs for development while contributing to a reduction in GHGs. Clean energy, in particular electrical energy, will be an essential contributor to the sustainability of future society. Nuclear energy generated by innovative nuclear reactors with new philosophies of safety and design will have an important role in bringing about sustainability.

\section{Global Warming}

The problem of global warming is no longer a philosophical discussion, but it is a fact seriously threatening the future of humanity. The energy conservation and alternative forms of energy such as solar, wind, and bio even though having important roles, do not satisfy the energy demand generated by an increasing world population that desires to increase its standard of living.

A UN panel on global warming made impressive observations: "As the scientific consensus on global warming grows, it's time to look more closely at how to share the economic, social, and humanitarian burdens that climate change will likely bring. If sea levels rise at the rates they are predicting, we may see hundreds of millions of refugees. Where will they go? Who will take them in? What does it mean about immigration regulations? These were only some of the moral and ethical questions that are being posed by the looming effects of global warming. The future will be catastrophic 
for all communities, for all countries, but particularly for those who have already been identified as particularly vulnerable to the impacts of climate change. Some forecasts suggest that small island states will disappear entirely under the rising ocean. This is the time to remind the international community that ethics and morality do play a very important role in any human activity, especially when we have a situation where climate change is affecting such a large number, especially the poor and vulnerable".

\section{Advantages of Small Nuclear Reactor}

Small nuclear reactors best satisfy the needs of the future world specially that of developing countries. At a particular point in time, when a necessity to limit the emissions of carbon dioxide is acknowledged by the majority of countries, small reactors will have a good chance to be implemented in many developing and industrialized countries and may contribute immensely to the sustainable development through electricity production, water desalination, and process heat applications.

Some of the important advantages of the small reactors may be summarized as follows:

- They are adequate for countries with small electric grids and insufficient infrastructure.

- They are adequate for countries that have limited capacities for investment, especially in relation to hard currency, and small turnover of capital in the electricity market.

- They offer an option of electricity generation coupled with seawater desalination, which meets the urgent needs of many developing countries.

- They could offer a variety of passive safety features that may be difficult to obtain with large reactors. This fact makes them a good potential choice for countries with insufficient nuclear infrastructure and a limited number of human resources.

- They provide an attractive domain for fuel leasing and facilitate an option of factory fuelled and transportable power plant, such as barge-mounted, which may be a solution for countries with limited capabilities in mastering nuclear fuel cycle, or for those who prefer to be just the end users of nuclear power.

- In industrialized countries, electricity market deregulation is calling for power generation flexibility that smaller reactors may offer.

- They are of particular interest for advanced future non-electric applications, such as hydrogen production, coal liquefaction, etc.

- They provide means for learning knowledge and technology from a small prototype plant.

- As nuclear reactors do not emit carbon dioxide, they will provide the developing and industrialized countries with sustainable development through electricity production, water desalination and process heat applications.

- Small nuclear reactors such as the Fixed Bed Nuclear Reactor (FBNR) are adequate for sea water desalination as well as generation of electricity. There are two types of co-generation schemes: series and parallel. The series co-generation scheme requires relatively low investment and has an inherently higher efficiency while the parallel co-generation has a higher flexibility than the series method, but a lower efficiency [7]. 


\section{INPRO and Sustainability}

INPRO is the International Project on Innovative Nuclear Reactors and Fuel Cycles initiated by the International Atomic Energy Agency (IAEA) [8]. The objective of INPRO is to support the safe, sustainable, economic and proliferation resistant use of nuclear technology to meet the global energy needs of the 21 st century. The IAEA has committed itself to "Help to ensure that nuclear energy is available to contribute in fulfilling energy needs in the 21 st century in a sustainable manner; and to bring together both technology holders and technology users to consider jointly the international and national actions required to achieve desired innovations in nuclear reactors and fuel cycles". INPRO considers sustainability as a holistic approach in terms of economy, safety, environment, physical protection, waste management, proliferation resistance, and infra-structure. INPRO is destined to bring about a new era of nuclear energy.

\section{FBNR Nuclear Reactor}

The Fixed Bed Nuclear Reactor (FBNR) is a small reactor $(70 \mathrm{MWe})$ without the need of on-site refueling. It utilizes the pressurized water reactor (PWR) technology. It has the characteristics of being simple in design, inherently safe, passive cooling, proliferation resistant, and reduced environmental impact [9-16].

The FBNR fuel chamber is fuelled in the factory. The sealed fuel chamber is then transported to and from the site. The FBNR has a long fuel cycle time and there is no need for onsite refueling. The reactor makes extensive use of PWR technology. It is an integrated primary system design.

FBNR Nuclear Reactor is an innovative nuclear reactor that meets all the INPRO criteria and philosophy. Small reactors have the advantages of serving the needs of local communities, need low capital investment and do not require expensive power transmission system. FBNR can serve as a multipurpose plant producing electricity, desalinated water, industrial steam, and supply district heating simultaneously. FBNR is inherently safe that implies total safety and environmentally friendly. The used fuel of FBNR may not be considered nuclear waste since it can serve as a source of radiation for irradiation purposes which has useful application in agriculture, medicine and industry.

FBNR is a foolproof non-proliferating reactor that cannot be misused for military purposes. It is economic with low capital investment. It can contribute to the solution of ever increasing demand for energy in a world that is in the grip of an economic crisis. FBNR uses the well proven PWR technology. The countries that adopt FBNR will participate in the research and development of the technology and become the owners of nuclear technology and not merely the users. Science may be transferred, but technology is not transferable - it is developed.

The newcomer countries to nuclear energy can participate in the development of FBNR while they are implementing the IAEA Milestones Guidelines [17]. Any country can become a stakeholder in the FBNR project. Participation in the FBNR project brings with it sophisticated technology and wealth to the country. It will also have a positive impact on other industries in that country.

The inherent safety and passive cooling characteristics of the FBNR nuclear reactor eliminate the need for containment. However, an underground containment is envisaged for the reactor to mitigate any imagined adverse event, but mainly to help with the visual effects by hiding the industrial equipment 
underground and presenting the nuclear plant as a beautiful garden compatible with an environment which would be acceptable to the public. The reactor can be operated with a reduced number of operators or even be remotely operated without any operator on site. The FBNR fuel chamber is fuelled in the factory. The sealed fuel chamber is then transported to and from the site.

\subsection{Reactor Description}

The reactor as shown in the schematic Figure 1, has in its upper part the reactor core and a steam generator and in its lower part the fuel chamber. The core consists of two concentric perforated zircaloy tubes of $31 \mathrm{~cm}$ and $171 \mathrm{~cm}$ in diameters, inside which, during the reactor operation, the spherical fuel elements are held together by the coolant flow in a fixed bed configuration, forming a suspended core. The coolant flows vertically up into the inner perforated tube and then, passing horizontally through the fuel elements and the outer perforated tube, enters the outer shell where it flows up vertically to the steam generator. The reserve fuel chamber is a $60 \mathrm{~cm}$ diameter tube made of high neutron absorbing alloy, which is directly connected underneath the core tube. The fuel chamber consists of a helical $40 \mathrm{~cm}$ diameter tube flanged to the reserve fuel chamber that is sealed by the national and international authorities. A grid is provided at the lower part of the tube to hold the fuel elements within it. A steam generator of the shell-and-tube type is integrated in the upper part of the module. A control rod can slide inside the centre of the core for fine reactivity adjustments. The reactor is provided with a pressurizer system to keep the coolant at a constant pressure. The pump circulates the coolant inside the reactor moving it up through the fuel chamber, the core, and the steam generator. Thereafter, the coolant flows back down to the pump through the concentric annular passage. At a flow velocity called terminal velocity, the water coolant carries the $15 \mathrm{~mm}$ diameter spherical fuel elements from the fuel chamber up into the core. A fixed suspended core is formed in the reactor. In the shut down condition, the suspended core breaks down and the fuel elements leave the core and fall back into the fuel chamber by the force of gravity. The fuel elements are made of $\mathrm{UO}_{2}$ micro spheres embedded in SiC and cladded by zircaloy or stainless steel.

Any signal from any of the detectors, due to any initiating event, will cut-off power to the pump, causing the fuel elements to leave the core and fall back into the fuel chamber, where they remain in a highly subcritical and passively cooled conditions. The fuel chamber is cooled by natural convection transferring heat to the water in the tank housing the fuel chamber.

The pump circulates the water coolant in the loop and at the mass flow rate of about $220 \mathrm{~kg} / \mathrm{sec}$, corresponding to the terminal velocity of $1.50 \mathrm{~m} / \mathrm{sec}$ in the reserve fuel chamber, carries the fuel elements into the core and forms a fixed bed. At the operating flow velocity of $7.23 \mathrm{~m} / \mathrm{sec}$, corresponding to the mass flow rate of $1060 \mathrm{~kg} / \mathrm{sec}$, the fuel elements are firmly held together by a pressure of 0.188 bars that exerts a force of 27.1 times its weight, thus forming a stable fixed bed. The fixed bed is compacted by a pressure of 1.3 bars. The coolant flows radially in the core and after absorbing heat from the fuel elements enters the integrated heat exchanger of tube and shell type. Thereafter, it circulates back into the pump and the fuel chamber. The long-term reactivity is supplied by fresh fuel addition and possibly aided by a fine control rod that moves in the center of the core controls the short-term reactivity. A piston type core limiter adjusts the core height and controls the amount of fuel elements that are permitted to enter the core from the reserve chamber. The control 
system is conceived to have the pump in the "not operating" condition and only operates when all the signals coming from the control detectors simultaneously indicate safe operation. Under any possible inadequate functioning of the reactor, the power does not reach the pump and the coolant flow stops causing the fuel elements to fall out of the core by the force of gravity and become stored in the passively cooled fuel chamber. The water flowing from an accumulator, which is controlled by a multi redundancy valve system, cools the fuel chamber functioning as the emergency core cooling system. The other components of the reactor are essentially the same as in a conventional pressurized water reactor. Detailed technical information is presented in Table 1.

Figure 1. Schematic Design of the Fixed Bed Nuclear Reactor (FNBR).
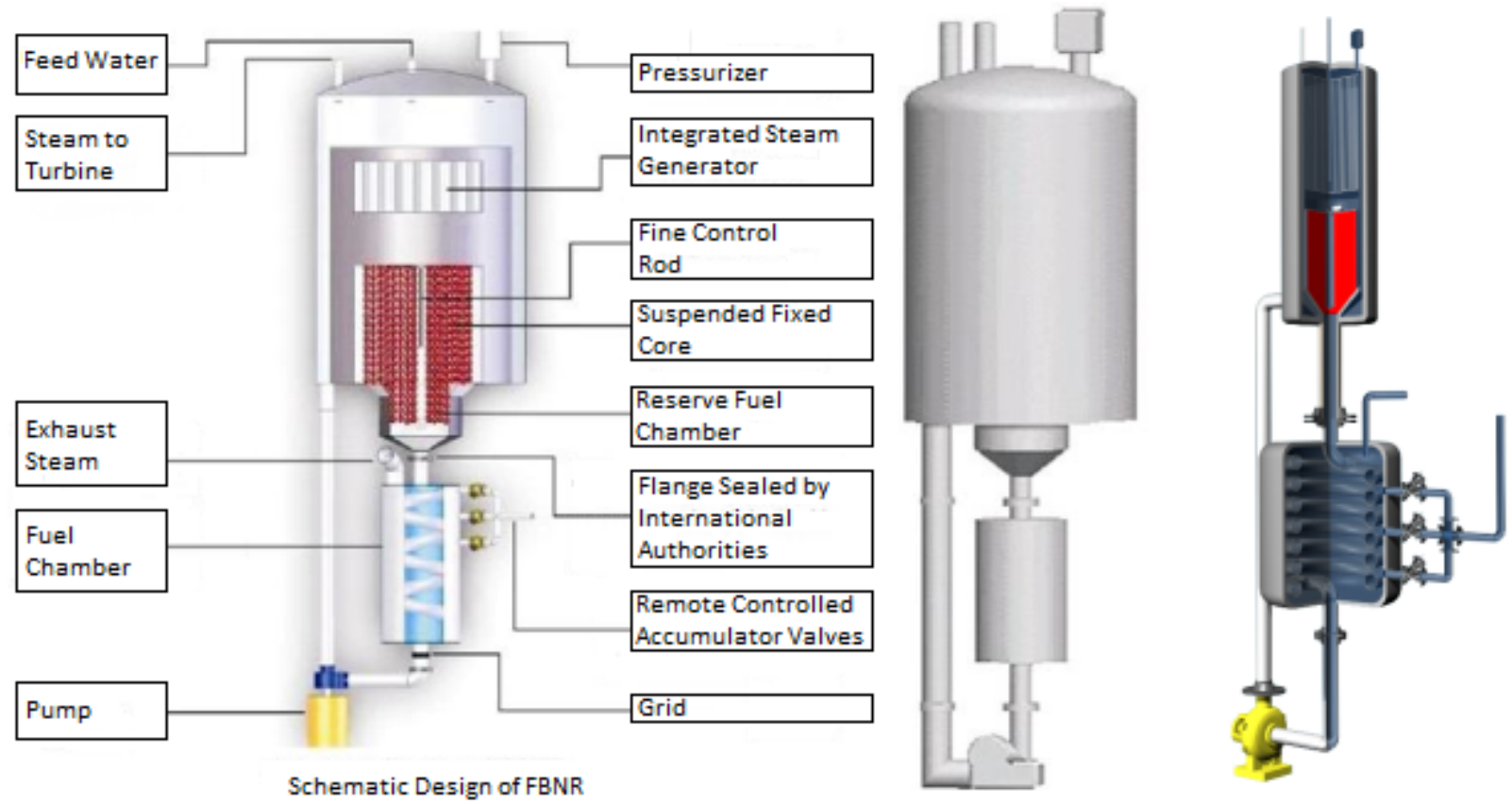

Figure 2. Underground Containment.

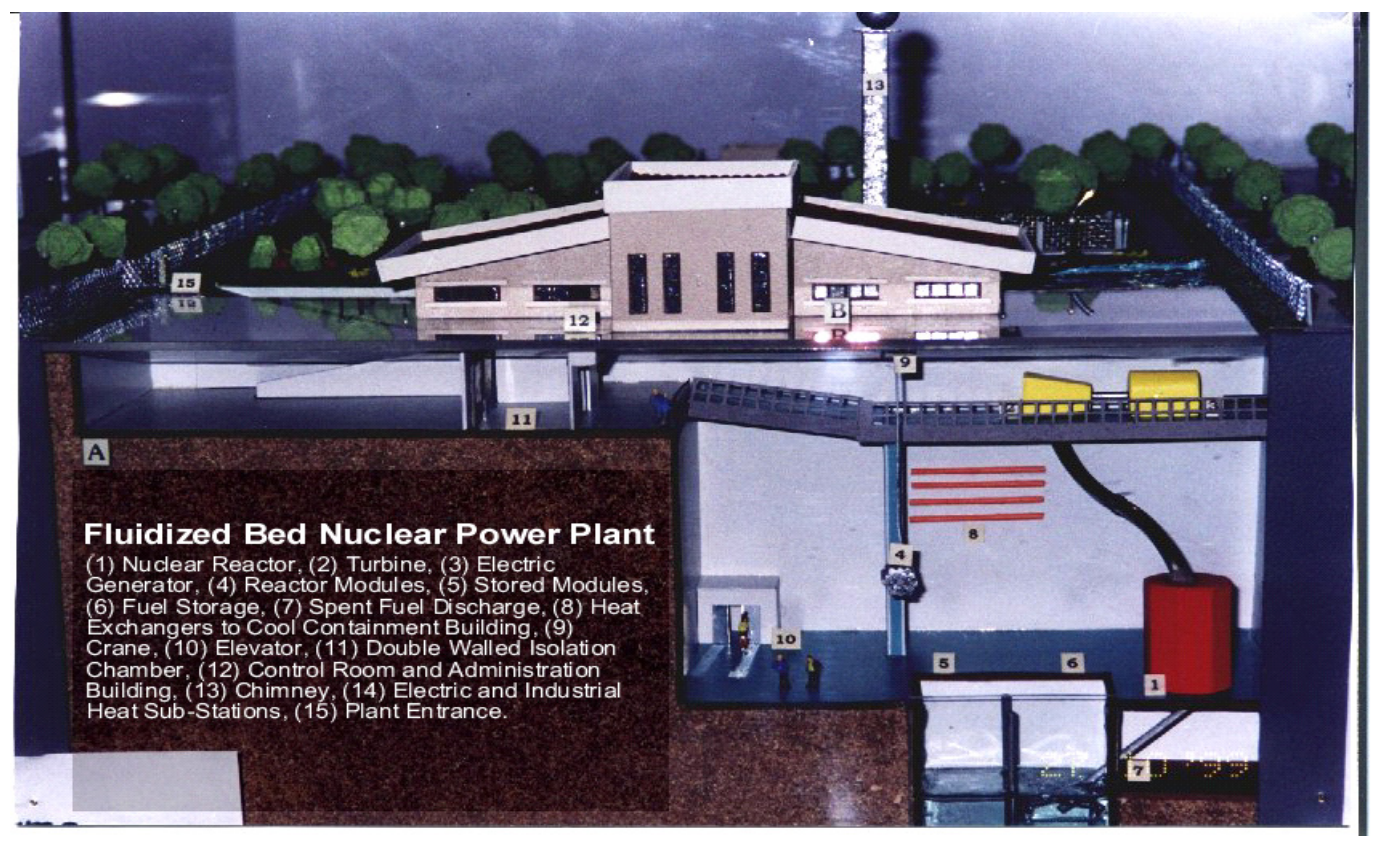


Table 1. Technical data for the Fixed Bed Nuclear Reactor (FBNR).

\begin{tabular}{|c|c|c|c|}
\hline Parameter & Value & Parameter & Value \\
\hline Power & & $\begin{array}{l}\text { Coolant temperature rise after a LOFA } \\
\text { after } 10 \text { days }\left({ }^{\circ} \mathrm{C}\right)\end{array}$ & $<1$ \\
\hline Net power generation (MWe) & 70 & $\begin{array}{l}\text { Water needed to cool during } 10 \text { days } \\
\text { after LOCA }\left(\mathrm{m}^{3}\right)\end{array}$ & 0.9 \\
\hline Thermal power generation (MWt) & 218 & Neutronics & \\
\hline Core power density (KWt/lit) & 45.6 & Moderator Coefficient $\left(\mathrm{mK} /{ }^{\circ} \mathrm{C}\right)-\mathrm{BOC}$ & $-3 \times 10^{-4}$ \\
\hline Pump power (MWe) & 2 & Moderator Coefficient $\left(\mathrm{mK} /{ }^{\circ} \mathrm{C}\right)-\mathrm{EOC}$ & $-8 \times 10^{-4}$ \\
\hline Hydraulics & & Doppler Coefficient $\left(\mathrm{mK} /{ }^{\circ} \mathrm{C}\right)$-EOC & $-7 \times 10^{-5}$ \\
\hline Coolant volume $\left(\mathrm{m}^{3}\right)$ & 10 & $\begin{array}{l}\text { Core height level limiter (CHLL) } \\
\text { Sensitivity }(\mathrm{mK} / \mathrm{cm}) \text { - BOC }\end{array}$ & 0.37 \\
\hline Coolant mass flow $(\mathrm{kg} / \mathrm{sec})$ & 1,060 & $\begin{array}{l}\text { Core height level limiter (CHLL) } \\
\text { Sensitivity }(\mathrm{mK} / \mathrm{cm}) \text {-EOC }\end{array}$ & 0.059 \\
\hline Coolant pressure (bar) & 160 & Boron Sensitivity (mK/ppm)-BOC & 0.039 \\
\hline Pressure loss in the loop (bar) & 12.3 & Boron Sensitivity (mK/ppm)—EOC & 0.080 \\
\hline Pressure loss in the bed (bar) & 1.3 & Fuel Burnup [MWD/T/Years] & $15,300 / 2.2$ \\
\hline Terminal velocity $(\mathrm{m} / \mathrm{sec})$ & 1.5 & Plutonium Production $(\mathrm{Kg})$ & 62 \\
\hline Operating coolant velocity $(\mathrm{m} / \mathrm{sec})$ & 7.23 & Remaining U-235 (Kg) & 340 \\
\hline Thermal & & Core dimensions & \\
\hline Coolant inlet temperature $\left({ }^{\circ} \mathrm{C}\right)$ & 290 & Core height $(\mathrm{cm})$ & 200 \\
\hline Coolant outlet temperature $\left({ }^{\circ} \mathrm{C}\right)$ & 326 & Core inner diameter $(\mathrm{cm})$ & 31 \\
\hline Coolant average temperature $\left({ }^{\circ} \mathrm{C}\right)$ & 308 & Core outer diameter $(\mathrm{cm})$ & 171 \\
\hline Fuel operating temperature $\left({ }^{\circ} \mathrm{C}\right)$ & 354 & Core volume $\left(\mathrm{m}^{3}\right)$ & 4.78 \\
\hline Coolant inlet enthalpy $(\mathrm{kJ} / \mathrm{kg})$ & 1,284 & Fuel Element in the core (Ton) & 23.2 \\
\hline Coolant inlet density $\left(\mathrm{kg} / \mathrm{m}^{3}\right)$ & 747 & $\mathrm{UO} 2$ in the core (Ton) & 11.5 \\
\hline Coolant average density $\left(\mathrm{Kg} / \mathrm{m}^{3}\right)$ & 710 & Fuel element & \\
\hline Enthalpy rise in the core $(\mathrm{kJ} / \mathrm{kg})$ & 1,490 & Fuel element diameter $(\mathrm{cm})$ & 1.5 \\
\hline $\begin{array}{l}\text { Film boiling convective heat transfer coefficient } \\
\text { at } 300^{\circ} \mathrm{C}\left(\mathrm{W} / \mathrm{m}^{2} \cdot{ }^{\circ} \mathrm{C}\right)\end{array}$ & 454 & Zircaloy clad thickness $(\mathrm{cm})$ & 0.03 \\
\hline $\begin{array}{l}\text { Fuel element average thermal conductivity } \\
\left(\mathrm{W} / \mathrm{m} \cdot{ }^{\circ} \mathrm{C}\right)\end{array}$ & 12.5 & Number of fuel elements in the core. & $1.62 \times 106$ \\
\hline Thermal conductivity Zirconium $\left(\mathrm{W} / \mathrm{m} \cdot{ }^{\circ} \mathrm{C}\right)$ & 18 & $\mathrm{UO} 2$ in each fuel element ( $\% \mathrm{vol})$ & 23.9 \\
\hline Thermal conductivity Uranian Dioxide $\left(\mathrm{W} / \mathrm{m} \cdot{ }^{\circ} \mathrm{C}\right)$ & 7 & $\mathrm{UO} 2$ density $\left(\mathrm{gr} / \mathrm{cm}^{3}\right)$ & 10.5 \\
\hline Fuel element average specific heat $\left(\mathrm{J} / \mathrm{kg} \cdot{ }^{\circ} \mathrm{C}\right)$ & & Zirconium $\left(\mathrm{gr} / \mathrm{cm}^{3}\right)$ & 6.5 \\
\hline
\end{tabular}

\subsection{Fuel Element Description}

The CERMET fuel is proposed for the FBNR reactor. The fuel consists of coated UO2 kernels embedded in a zirconium matrix, which is then coated with a protective outer zirconium layer. CERMET Fuels have significant potential to enhance fuel performance because of low internal fuel temperatures and low stored energy. The combination of these benefits with the inherent proliferation resistance, high burnup capability, and favorable neutronics properties of the thorium fuel cycle produces intriguing options for using thoria based cermet nuclear fuel in advanced nuclear fuel cycles.

The FBNR fuel element consists of 500 microns in diameter UO2 microspheres covered by 25 microns thick zirconium cladding embedded in a spherical zirconium matrix that is cladded by 
300 microns thick Zircaloy-4 cladding to form a $15 \mathrm{~mm}$ diameter fuel element. The option of SiC matrix and stainless steel cladding is also being considered.

\subsection{Reactor Control}

Signals transmitted from a multitude of detectors and fed into the control system will make the FBNR a totally safe nuclear reactor, and guard it against, sabotage, terrorist action, explosion, earthquake, flooding, fire, tornado, or any other natural or man-made disaster. Any abnormal signal outside the range of operation from any of the detectors will signal an accident alarm which in turn will automatically cut off power to the pump resulting in the fuel elements to fall out of the reactor core, by the force of gravity, and become stored safely in the passively cooled fuel chamber.

\section{Neutronics Calculations}

The reactor physics calculations are made using the SCALE computational codes. SCALE (Standardized Computer Analyses for Licensing Evaluation) is a modular code system that was originally developed by Oak Ridge National Laboratory (ORNL). The SCALE system utilizes well-established computer codes and methods within standard analysis sequences that: (1) Provide an input format designed for the occasional user and/or novice, (2) Automate the data processing and coupling between modules, and (3) Provide accurate and reliable results.

The results of Ke as a function of boron concentration for cold and hot reactor are shown in Figure 3.

Figure 3. Schematic figure of inherently safe non-proliferating nuclear reactor.

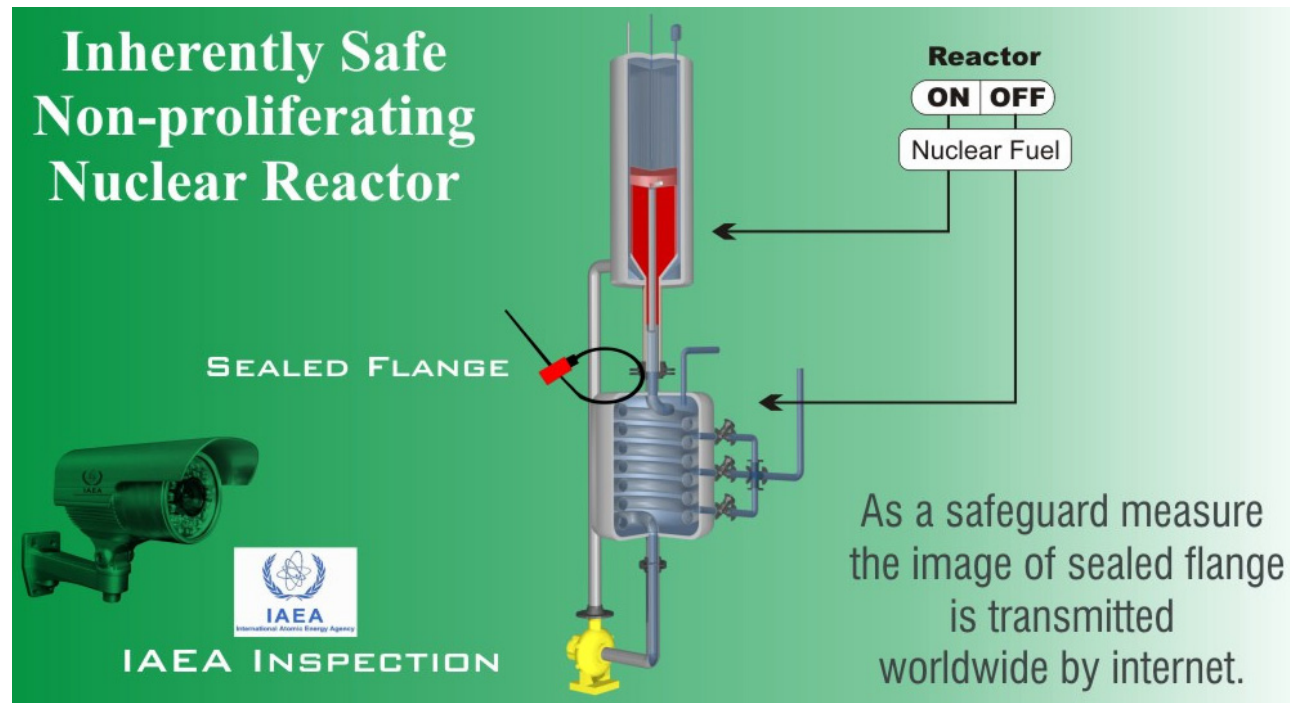

The neutron multiplication factor of the reactor as a function of core height for various boron concentrations of 0, 1000, 2000 and 3000 ppm are shown in Figure 4.

It is seen that the height up to about $120 \mathrm{~cm}$, the core height has a significant influence on reactivity. At higher values the sensitivity is small. This helps the reactivity control by movement of core height level limiter (CHLL) without the need of having fine control rods. However, there is a need to use boron poison to reduce $\mathrm{k}_{\mathrm{eff}}$ at the beginning of the burnup cycle. The $\mathrm{Ke}$ as a function of the core height and boron concentrations are shown in Figure 4. 
The sensitivity of reactivity to the core height for different boron concentrations is shown in Figure 5. The excess reactivity as a function of U-235 enrichment is shown in Figure 6.

Figure 4. Ke as a function of boron concentration.

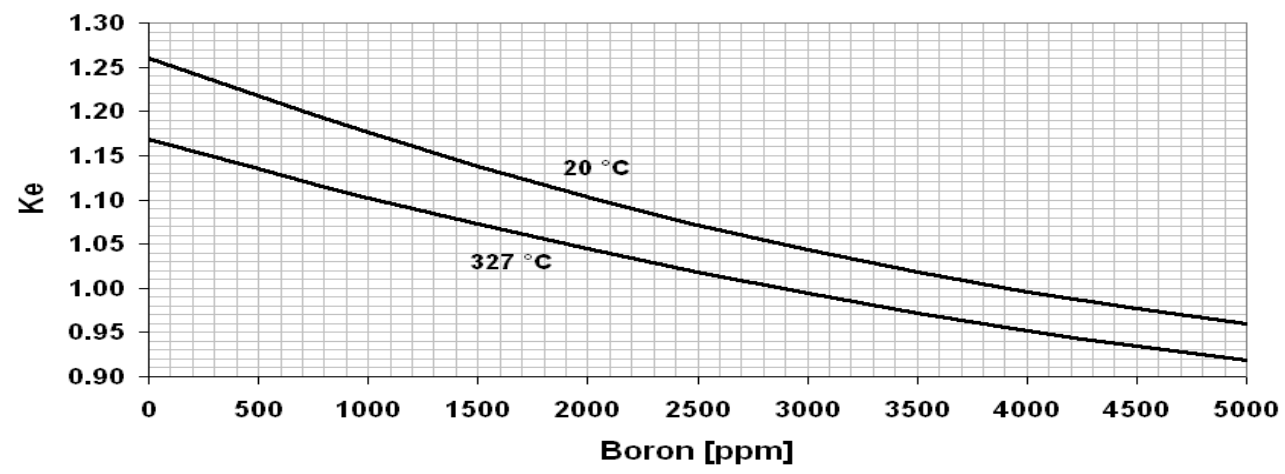

Figure 5. Ke as a function of the core height.

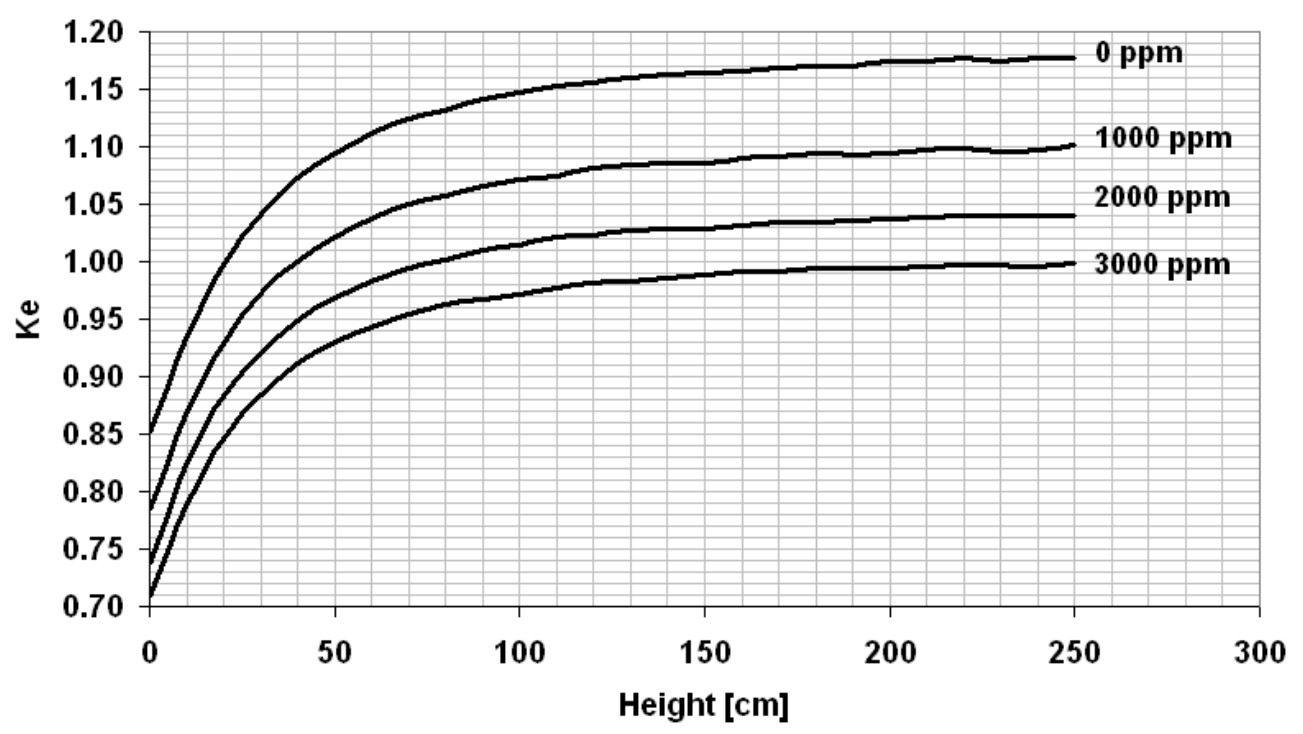

Figure 6. Sensitivity of reactivity to core height.

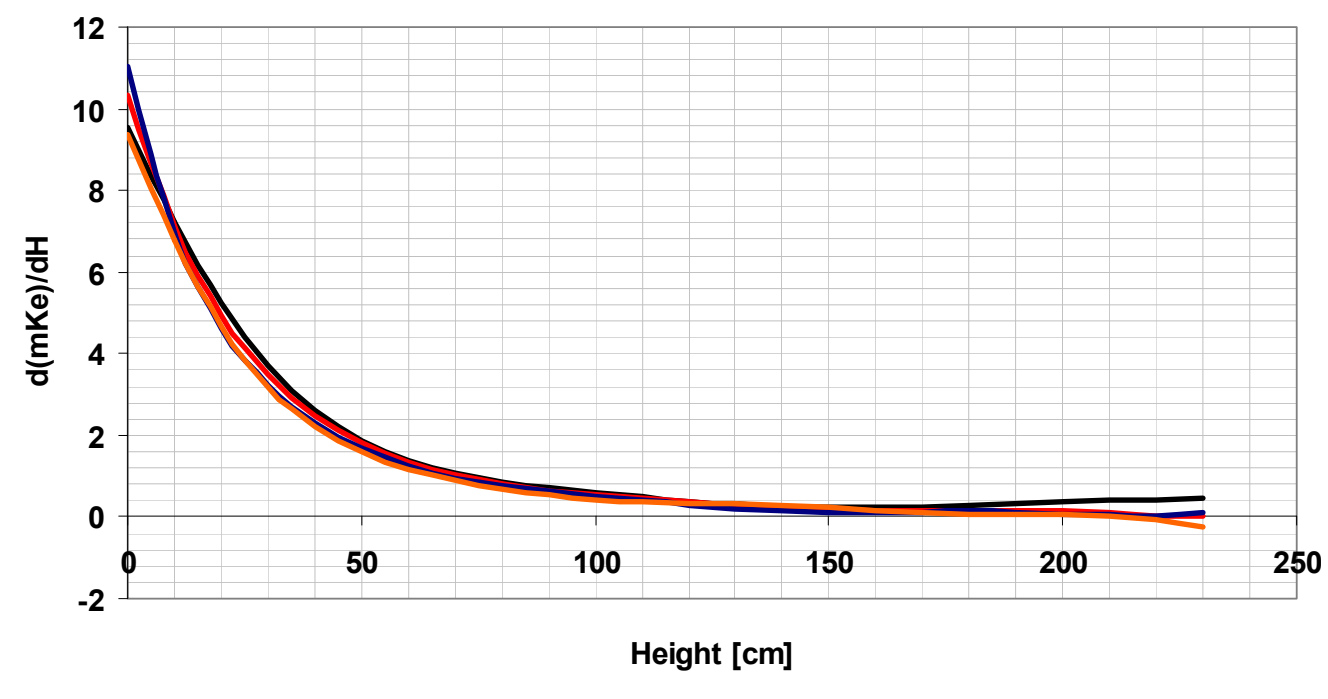

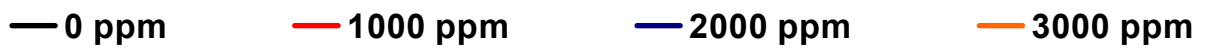




\subsection{Plutonium Utilization}

As a result of massive reductions in deployed nuclear warheads, and their subsequent dismantlement, large quantities of surplus weapons-grade plutonium are and will be stored until its ultimate disposition is achieved. The most efficient and effective way to dispose of surplus weapons-grade plutonium is to fabricate it into fuel and use it for generation of electrical energy in commercial nuclear power plants. Weapons-grade plutonium can be used as fuel in FBNR. This recovers energy and economic value from weapons-grade plutonium, which otherwise represents a large cost liability to maintain in safeguarded and secure storage. MOX fuels are well developed and are currently used in a number of LWRs. Plutonium-bearing fuels without uranium (non-fertile fuels) would require some development. The plutonium from the reprocessing of FBNR spent fuel will in the future be also a fuel resource. Here, the reactor is assumed to be fuelled by the plutonium coming from the reprocessing of FBNR spent fuel after 840 days of burnup. The fuel is thus composed of $95 \% \mathrm{U}-238$ and $5 \% \mathrm{Pu}$.

The calculated $\mathrm{Ke}$ as a function of core height and the percent $\mathrm{Pu}$ mixture in the fuel are presented in Figure 7 it shows a comparison between uranium and plutonium fuelled reactor in regards to the enrichment effects.

Figure 7. Excess of reactivity as a function of enrichment.

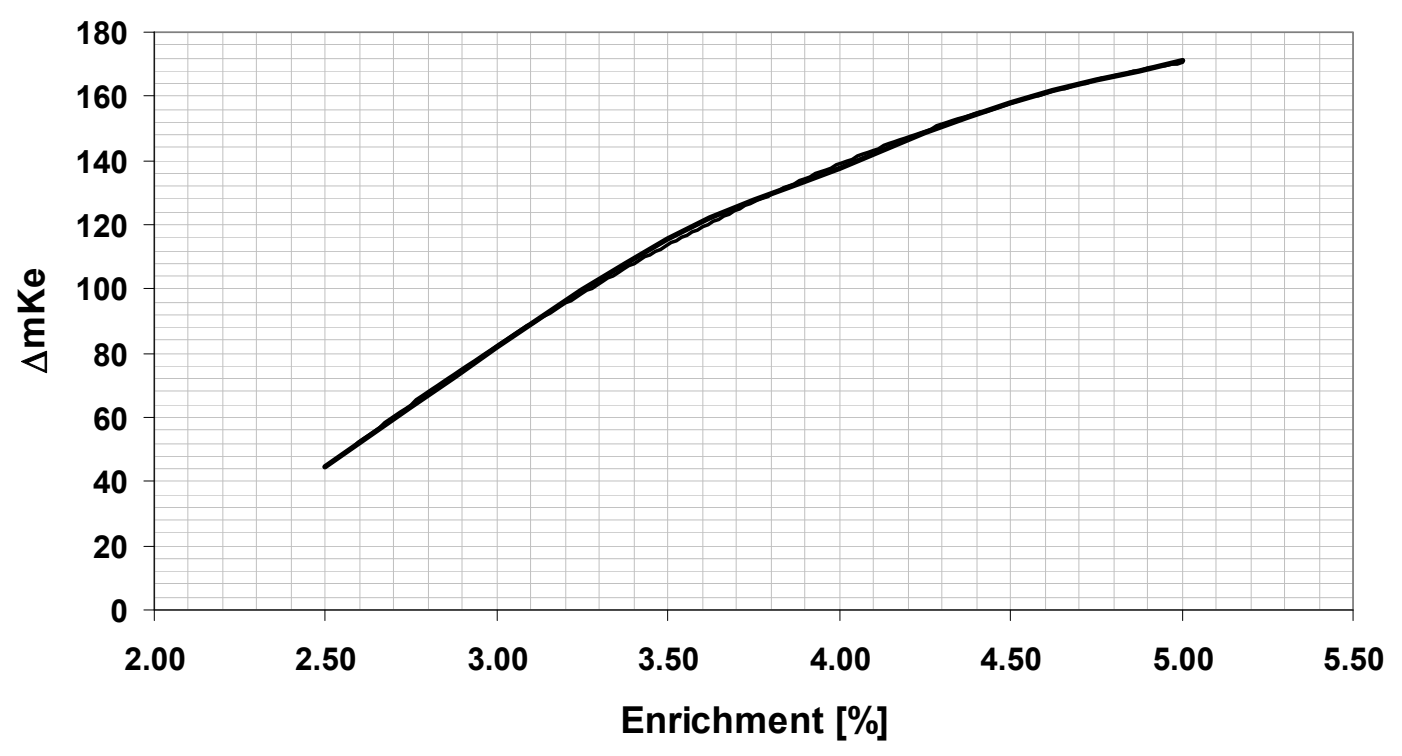

\subsection{Thorium Utilization}

World thorium reserves are estimated to be about 3 times more abundant than the natural uranium reserves. Utilization of thorium would make possible to exploit new nuclear fuel reserves. Further advantages of thorium would be enhanced nuclear safeguarding because thorium will be converted to uranium, a significantly benign material compared to plutonium with respect to safeguard considerations as well as radio toxicity. As thorium by itself is not a nuclear fuel, the $235 \mathrm{U}$ must serve as a booster fissile fuel material in a thermal reactor, fueled with thorium.

Thorium cycle produces $233 \mathrm{U}$ which, from a non-proliferation point of view, is more acceptable compared to plutonium for two reasons. Firstly, it is contaminated with 232U, which decays to give highly radioactive daughter products with very hard $\gamma$-ray radiation, which has already a very high 
level of deterrence and would make handling and diversion difficult. Secondly, the $233 \mathrm{U}$ could easily be denaturized by adding some $238 \mathrm{U}$ to the thorium, which would then eliminate the possibility to make a critical assembly with the bred fuel. In future, thorium may play a larger role in the nuclear fuel cycle. The superior nuclear properties of $233 \mathrm{U}$ over $235 \mathrm{U}$ and $239 \mathrm{Pu}$ in thermal reactors imply potential advantages to $233 \mathrm{U}$ in advanced reactors including FBNR.

Nuclear reactors produce nuclear waste materials in substantial quantities, which are classified as fission products, minor actinides (MA) and structural materials, where can be defined the most hazardous radioactive waste products because of their long term, high level radioactivity. A significant fraction of reactor waste MA consists of diverse plutonium isotopes, which represents serious public and political concern with respect to misuse of this plutonium and also accidental release of highly radiotoxic material in to the environment. Hence, precautions to keep plutonium under strong security have paramount importance. Some nuclear waste actinides $(239 \mathrm{Pu}, 241 \mathrm{Pu}, 242 \mathrm{mAm}$ and $245 \mathrm{Cm}$ ) are fissile fuel under thermal neutron spectrum, and all of them become fissile fuel under fast neutron spectrum.

Some other MA are moderately fissile even under thermal neutron spectrum $(238 \mathrm{Pu}, 241 \mathrm{Am}$ and $244 \mathrm{Cm}$ ). Hence, it is worth to investigate the incineration of MA in the FBNR. Figure 8 shows Ke as a function of core height.

The following Figure 9 shows $\mathrm{Ke}$ as a function of thorium dioxide mixed with uranium dioxide of $5 \%$ and $10 \%$ enrichment.

Figure 10 shows Ke as a function of core height for a mixture of $20 \%$ thorium $\left(\mathrm{ThO}_{2}\right)$ with uranium (UO2) of $10 \%$ enrichment.

Figure 8. Ke as a function of core height.

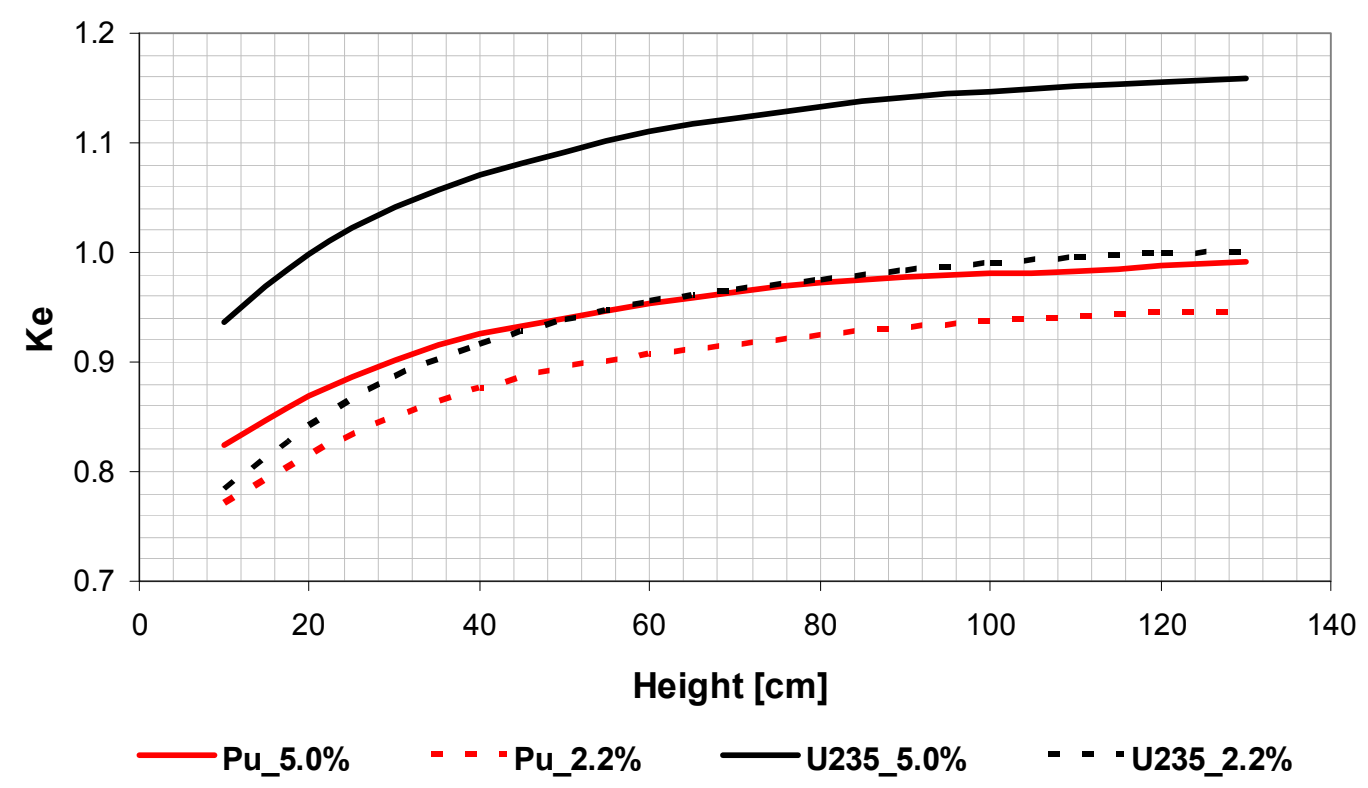


Figure 9. Comparison of uranium and plutonium fuelled reactor.

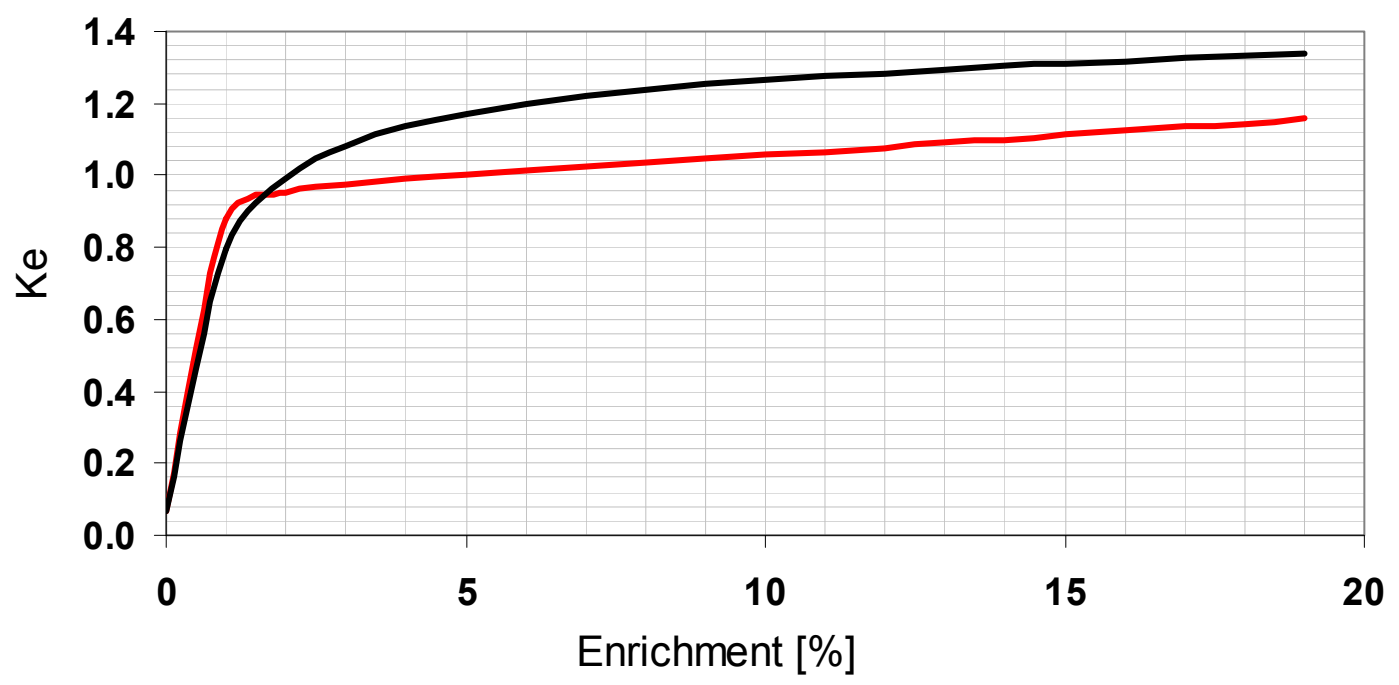

- Plutonium

-Uranium

Figure 10. Ke as a function of thorium concentrate.

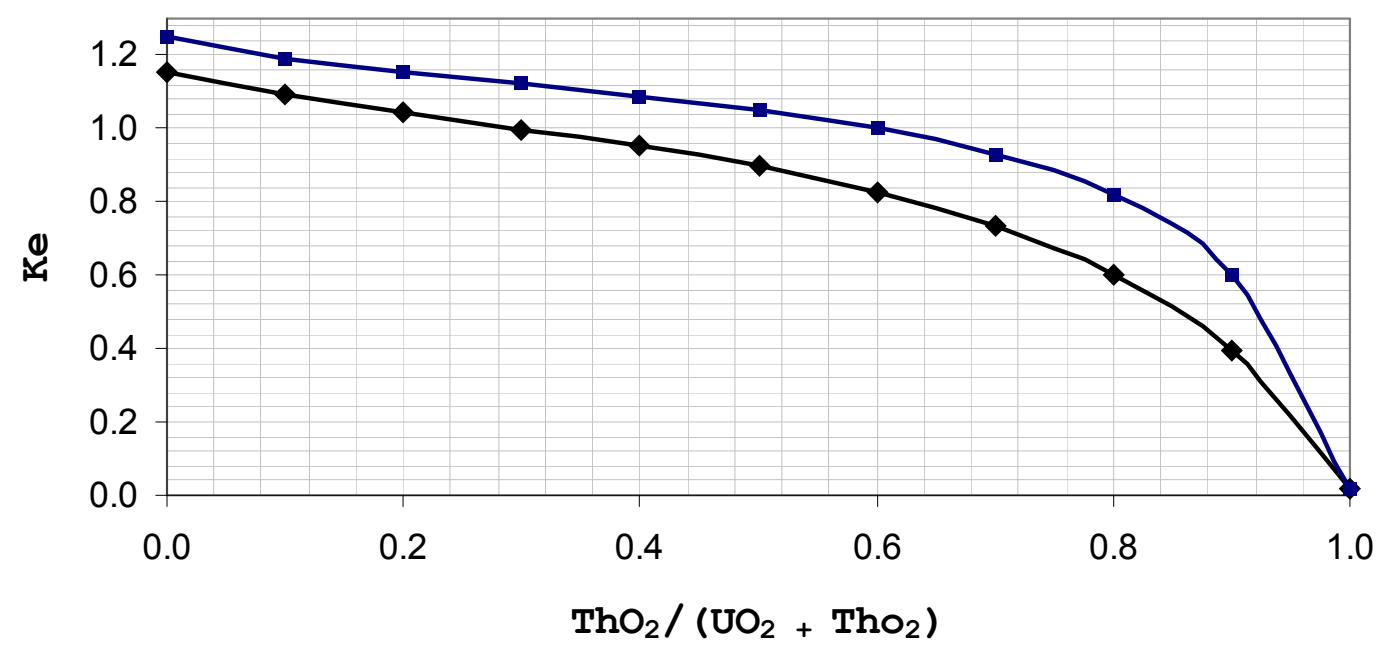

$\neg$ -

$\rightarrow-10 \%$ U235

\section{Thermal and Hydraulics Calculations of FBNR}

An important characteristic of this reactor concept is its relatively high coolant flow rate. Therefore, it is important to evaluate the pressure losses in different sections of the loop and devise methods to reduce them and come up with an optimized condition.

The size of the reactor depends on how large the coolant pump we accept to have and what percentage of the total reactor power produced, we would allow to be fed to the pump. Thus the limit of the reactor power is not dependent on the design temperatures but on the percent of pump power consumption. The standard reactor is chosen to be 70 MWe where about $3 \%$ of power is consumed by the pump. One can have a 100, 150, and maximum 165 MWe reactor accepting 6, 19, and 34\% of generated power going to powering the pump respectively. Above this maximum reactor size, the required pump power will exceed the additional energy produced by the reactor and thus the system 
become unproductive. One does not need to use a single pump, but can use a combination of pumps in parallel and series to meet the needs.

It is seen that in the operating condition of the $70 \mathrm{MWe}$ reactor, the fuel elements are held together with a pressure of about 0.2 bar and the force on them is more than 27 times the force of gravity, thus guarantees the bed to remain a fixed bed during the reactor operation.

Figure 11 shows the calculated pressure losses in the reactor. The operating condition of the $70 \mathrm{MWe}$ reactor corresponds to the coolant flow velocity of $7.2 \mathrm{~m} / \mathrm{s}$. The minimum coolant velocity of $1.5 \mathrm{~m} / \mathrm{s}$ being the terminal velocity for the fuel elements. The maximum flow velocity is $25 \mathrm{~m} / \mathrm{s}$ above which the reactor operation becomes impractical. Figure 12 shows pressure loss as a function of flow mass velocity. Figure 13 shows net power of the reactor as a function of coolant velocity.

Figure 11. Ke as a function of core height for $20 \%$ thorium and enrichment of $10 \%$.

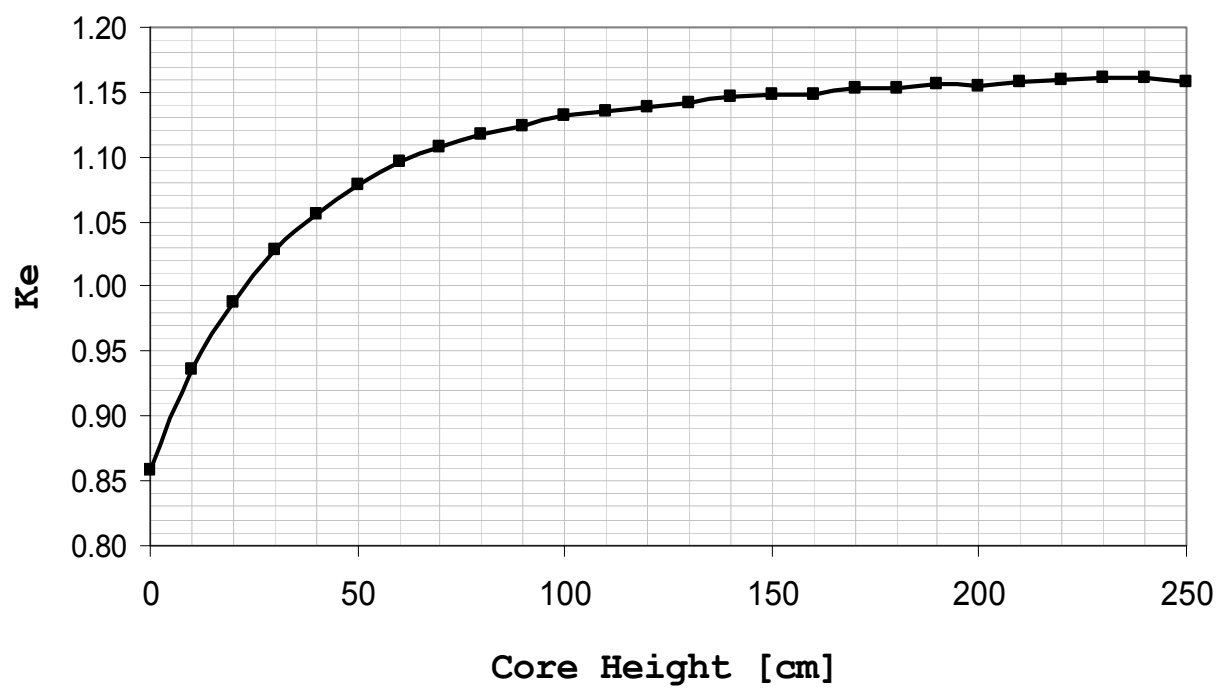

Figure 12. Calculated pressure losses.

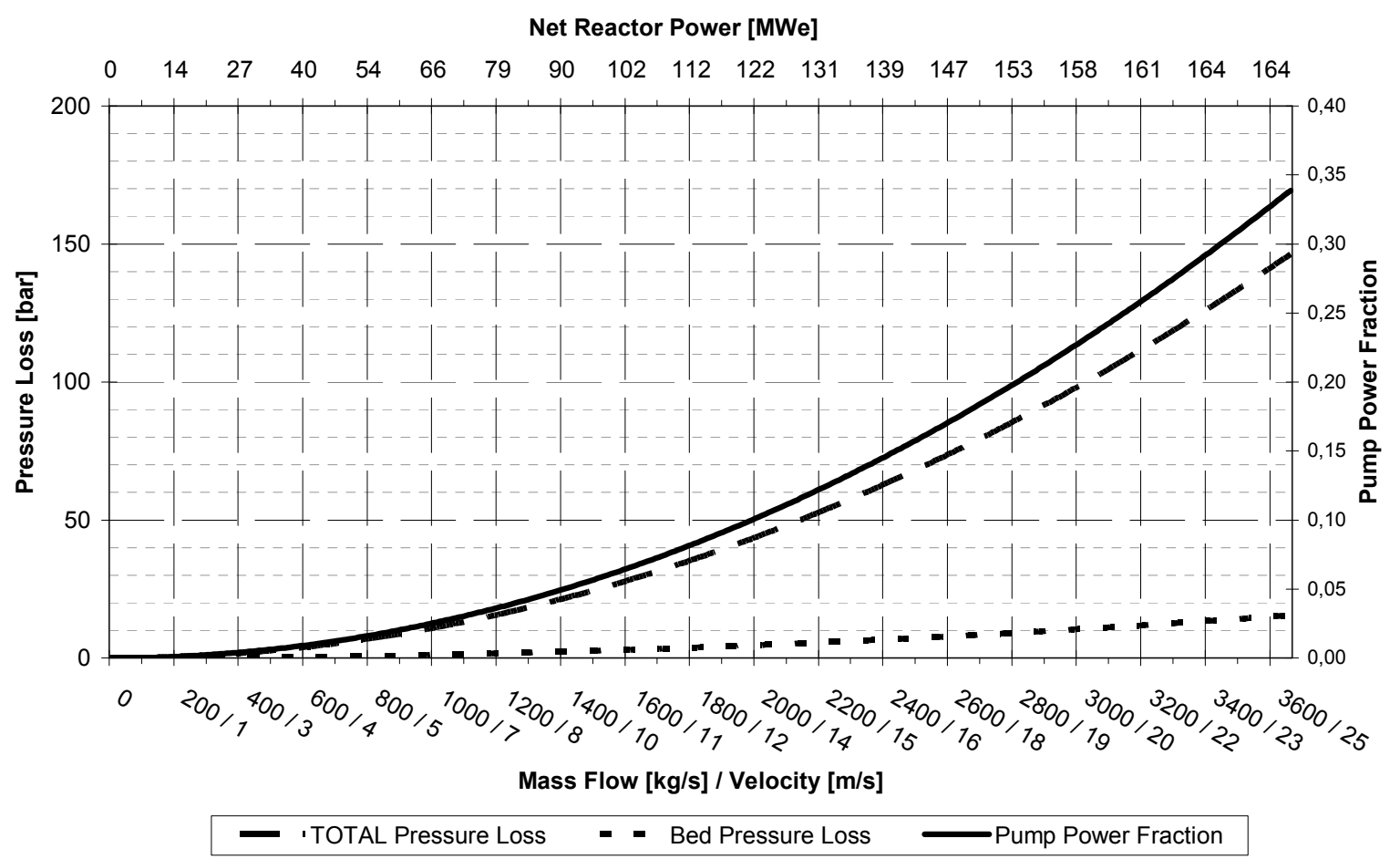


Figure 13. Reactor Power, Net Power and Mass Flow for the FBNR.

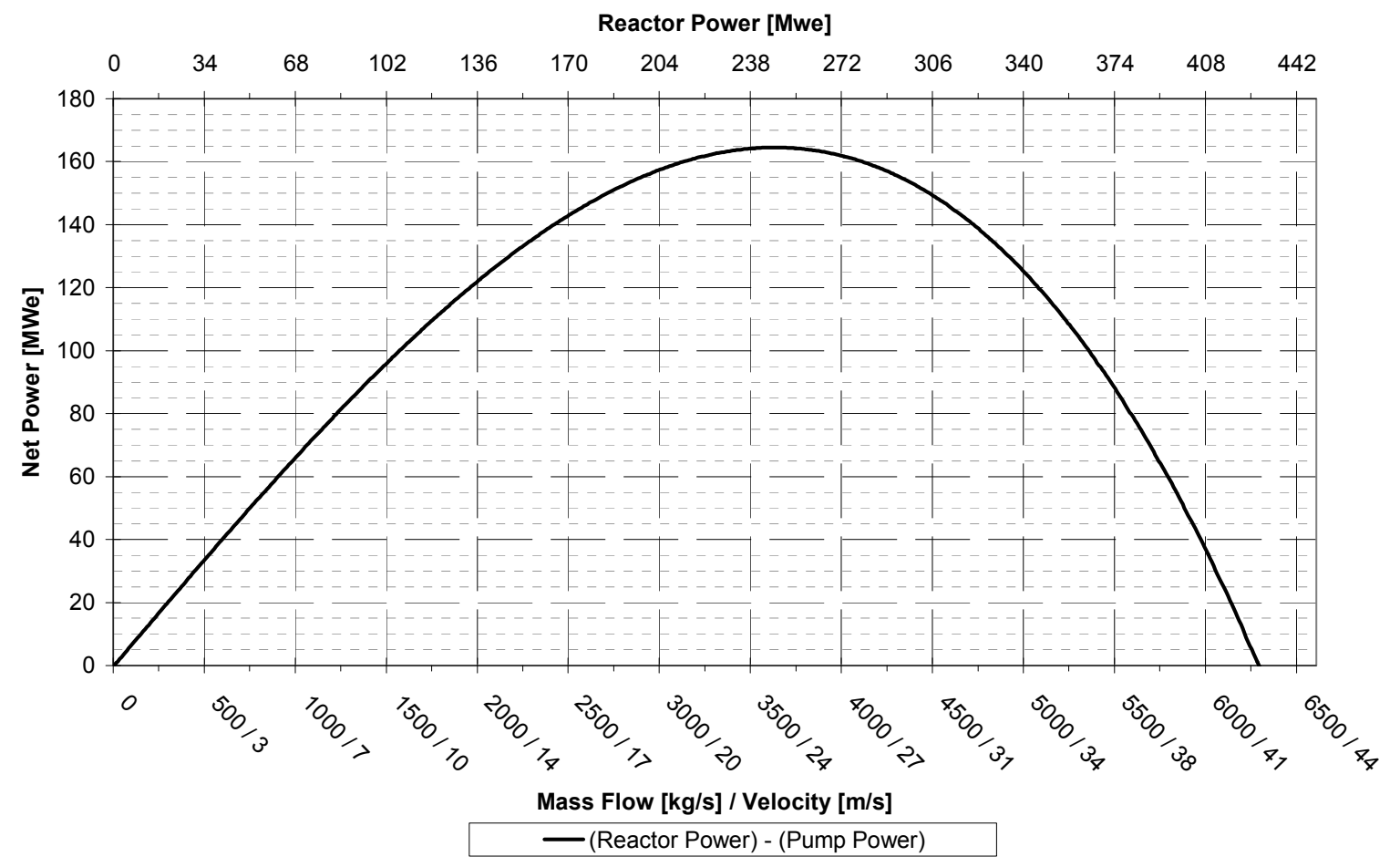

\section{Technical Summary}

The Fixed Bed Nuclear Reactor (FBNR) is an innovative small nuclear reactor $(70 \mathrm{MWe})$. The reactor is evaluated with the INPRO Methodology in respect to safety and non-proliferation aspects. The inherent safety and fool-proof non-proliferation characteristics of the reactor are demonstrated.

CERMET fuel is proposed for the FBNR reactor. The fuel consists of coated UO2 kernels embedded in a zirconium or SiC matrix, which is then coated with a protective outer zirconium layer or stainless steel. The $15 \mathrm{~mm}$ diameter spherical fuel elements are transported up into the reactor by the flow of water coolant creating a suspended core in the reactor. It is seen that in the operating condition of the $70 \mathrm{MWe}$ reactor, the fuel elements are held together with a pressure of about 0.2 bar and the force on them is more than 27 times the force of gravity, thus guarantees the bed to remain as a fixed bed during the reactor operation.

The operating condition of the $70 \mathrm{MWe}$ reactor corresponds to the coolant flow velocity of $7.2 \mathrm{~m} / \mathrm{s}$. The terminal velocity being the minimum coolant velocity to carry the fuel elements into the core is $1.5 \mathrm{~m} / \mathrm{s}$. The maximum flow velocity above which the reactor operation becomes impractical is of $25 \mathrm{~m} / \mathrm{s}$.

The inlet and outlet temperatures of coolant in the core are $290{ }^{\circ} \mathrm{C}$ and $326{ }^{\circ} \mathrm{C}$ corresponding to enthalpies of 1283 and $1489 \mathrm{KJ} / \mathrm{Kg}$ giving an enthalpy rise of $206 \mathrm{KJ} / \mathrm{kg}$. The mass coolant rate at the operating condition is $1060 \mathrm{Kg} / \mathrm{s}$ corresponding to a coolant velocity of $7.23 \mathrm{~m} / \mathrm{s}$, thus the reactor produces a thermal power of 218.4 MWt corresponding to an electric power of $70 \mathrm{MWe}$.

Any signal from any of the detectors, due to any accident event, wills cut-off power to the pump, causing the fuel elements to leave the core and fall back into the fuel chamber where they remain in a highly subcritical and passively cooled conditions. The fuel chamber is cooled by natural convection transferring heat to the water in the tank housing the fuel chamber. In this condition the accumulator 
valves, acting under pressure difference, will open automatically and the fuel chamber cooling tank becomes filled with cold water.

The critical core height is about $200 \mathrm{~cm}$. The core height can be changed by the Core Height Level Limiter (CHLL). The largest effect of CHLL is $0.37 \mathrm{mK} / \mathrm{Cm}$ at the beginning of cycle (BOC) and decreases to $0.059 \mathrm{mK} / \mathrm{Cm}$ at the end of cycle (EOC). The effect of soluble boron in the moderator is $0.039 \mathrm{mK} / \mathrm{ppmB}$ at the BOC. The $200 \mathrm{~cm}$ height reactor with $2900 \mathrm{ppmB}$ has $\mathrm{Ke}=0.99160$ and with 2700 has $\mathrm{Ke}=0.99981$.

It is seen that the moderator coefficient for $3000 \mathrm{ppm}$ is still negative being $-3 \times 10^{-4} \mathrm{mK} / \mathrm{C}$. The Doppler coefficient for $3000 \mathrm{ppm}$ boron is $-6 \times 10^{-5} \mathrm{mK} /{ }^{\circ} \mathrm{C}$. It is seen that each percent of fuel enrichment contribute to 281 days [5627 MWD/T] of the fuel lifetime.

In the case of a Loss of Coolant Accident (LOCA), the pressure in the reactor core drops and consequently the fuel elements fall out of the core and enter the fuel chamber where they remain under subcritical and passively cooled conditions. The heat transfer calculations show that their temperature will not exceed $\sim 542{ }^{\circ} \mathrm{C}$ and only less than $1 \mathrm{~m}^{3}$ of water from accumulator is necessary to evaporate during one month of grace period.

The Loss of Flow Accident (LOFA) will be a more favorable accident condition than the LOCA. Again the fuel elements due to the lack of coolant flow will fall back into the fuel chamber where they remain under subcritical and passively cooled conditions. There is no need for cooling water from accumulator to flow in, and the coolant in the loop will absorb the residual heat increasing its temperature by only less than $1{ }^{\circ} \mathrm{C}$.

The loss of power simply shuts down the pump and the reactor condition will be equivalent to a LOFA case.

The loss of turbine load or secondary loop break accident will cause the temperature of the cold leg of the pump increase and thus the control system will shut down the pump. Also the bubbles formed in the core decrease the moderator density thus due to the negative moderator coefficient, $\left(-350 \mathrm{mK} /\left(\mathrm{g} / \mathrm{cm}^{3}\right)\right)$, the reactor becomes subcritical.

The worst condition that any terrorist action can produce will be similar to the LOCA condition. What is needed will be to protect the fuel chamber physically within a robust structure.

As a result of massive reductions in deployed nuclear warheads, and their subsequent dismantlement, large quantities of surplus weapons- grade plutonium will be available. The use of $\mathrm{Pu}$ fuel in the FBNR reactor is studied and found to have a similar behavior to uranium fuel.

World thorium reserves are estimated to be about 3 times more abundant than the natural uranium reserves. Utilization of thorium for FBNR has been studied. It is seem that will enhance the non-proliferation characteristic of the FBNR reactor.

The limit of the reactor power is not dependent on the design temperatures but on the percent of pump power consumption. The standard reactor is chosen to be $70 \mathrm{MWe}$ where about $3 \%$ of power is consumed by the pump. One can have a maximum 165 MWe reactor should we accept that $34 \%$ of generated power goes to power the pump. Above this reactor size, the required pump power will exceed the additional energy produced by the reactor and thus the system become unproductive.

The $200 \mathrm{~cm}$ height core has $4.78 \mathrm{~m}^{3}$ volume and contains $2.87 \mathrm{~m}^{3}$ fuel that corresponds to 1.62 millions of spherical fuel elements. The volumetric heat generation is $76.10 \mathrm{w} / \mathrm{cm}^{3}$ or 134.40 watts per sphere. Each fuel element having $7.4 \mathrm{~g}$ of UO2 contain $6.52 \mathrm{~g}$ of uranium metal. 
Under normal operating condition, the temperature of the fuel surface is $357.7{ }^{\circ} \mathrm{C}$ corresponds to the temperature of $414.3{ }^{\circ} \mathrm{C}$ at fuel centre giving a temperature difference of $56.6^{\circ} \mathrm{C}$. The critical heat flux is found to be $2290 \mathrm{~kW} / \mathrm{m}^{2}$.

The FBNR is a land-based nuclear power plant for urban or remote localities. The FBNR is designed to produce electricity alone or to operate as a cogeneration plant producing simultaneously: electricity, desalinated water, steam for industrial purposes and heat for district heating. A MultiEffect Distillation (MED) plant may be used for water desalination. An estimated $1000 \mathrm{~m}^{3} /$ day of potable water could be produced at $1 \mathrm{MW}$ (e) reduction of the electric power.

\section{Reactor Safety}

It is very desirable to develop nuclear reactor concepts that are inherently safe whose safety features are easily demonstrable without depending on the interference of active safety devices which have some probability of failing, or depend on operator skills and good judgment, which could vary considerably.

There are only four significant sources of energy in a reactor accident: Nuclear power excursion, thermal reactions (steam explosion), chemical reactions (zirconium/water and core/concrete), and radioactive decay heat. The first three can be limited or controlled by proper selection of materials-a form of inherent safety. The fourth energy source, decay heat, is a slow and inherently restricted form of energy release.

All current reactors need to include safety systems to remove decay or residual heat produced after the chain reaction in a reactor has ceased. It is this decay heat that threatens to produce the most serious of nuclear accidents namely the core melt. The inherently safe reactors such as FBNR are transparently incapable of producing a core melt. They are "forgiving" reactors, able to tolerate human and mechanical malfunctions without endangering public health. Also such reactors are called "walk away" reactors as the key feature of these reactors is their reliance upon passive or non-mechanical, safety systems.

For FBNR any conceivable accident results in the cutting off the power to the pump that causes the fuel elements to fall out of the core by the force of gravity and enter the fuel chamber where they remain under subcritical and passively cooled conditions. The normal state of control system is "switch off". The pump is "on" only when all the operating conditions are simultaneously met.

The spherical fuel elements of HTGR type are fixed in the suspended core by the flow of water coolant. Any malfunction in the reactor system will cut off the power to the coolant pump causing a stop in the flow. This results in making the fuel elements fall out of the reactor core by the force of gravity and become stored in the passively cooled fuel chamber under sub critical condition.

\section{Fool Proof Non-Proliferation Nuclear Reactor}

Under the present world conditions, the first priority of the governments in relation to nuclear energy is non-proliferation and safeguard of the nuclear reactors. This provides a challenge for the scientists and technologists to come up with a fool proof nuclear reactor concept.

Both the International Project on Innovative Nuclear Reactors and Fuel Cycles (INPRO) of IAEA and the Generation IV International Forum (GIF) present methodologies for the evaluation of nuclear reactors in respect to resistance to nuclear proliferation (PR) and physical protection (PP). 
The IAEA through its INPRO recommends "proliferation resistant features and measures should be provided in innovative nuclear energy systems to minimize the possibilities of misuse of nuclear materials for nuclear weapons. Both intrinsic features and extrinsic measures are essential, and neither should be considered sufficient in itself. Extrinsic proliferation resistance measures, such as control and verification measures will remain essential, whatever the level of effectiveness of intrinsic features. From a proliferation resistance point of view, the development and implementation of intrinsic features should be encouraged. Communication between stakeholders will be facilitated by clear, documented and transparent methodologies for comparison or evaluation/assessment of proliferation resistance" [18-22].

FBNR is a small reactor and can be designed to have a very long core life. Small Reactors without On-Site Refueling are defined as reactors which have a capability to operate without refueling and reshuffling of fuel for a reasonably long period consistent with the plant economics and energy security, with no fresh and spent fuel being stored at the site outside the reactor during its service life. They also should ensure difficult unauthorized access to fuel during the whole period of its presence at the site and during transportation, and design provisions to facilitate the implementation of safeguards.

FBNR being a Small Reactor without On-Site Refueling will be factory produced and fueled and brought back to the factory for refueling after its fuel lifetime expires. FBNR modules are fabricated, fueled, and sealed in the factory under the supervision of the IAEA safeguard program. They are taken to the site and installed in the reactor and will return to the factory as sealed for refueling. This should assure the safeguard of the nuclear fuel. Adopting a thorium cycle as an intrinsic measure will hinder the possibility of misuse of nuclear materials for nuclear weapons. The mixing of thorium with low enriched uranium or plutonium results in the production of U-233 that is diluted along with U-235 in U-238. The access to uranium-233 will only be possible through isotope separation techniques. Additionally the production of gamma emitting Tl-208 in the thorium cycle is hindrance to nuclear proliferation.

If the U-Pu cycle is applied, one can increase the $\mathrm{Pu}-238$ concentration by adding $\mathrm{Np}$ to the fresh fuel. From a certain concentration of $\mathrm{Pu}-238$ on $(\sim 8 \%)$, the alpha decay heat is so strong that the metallic Pu-sphere, as well as the surrounding chemical explosives, in a nuclear device become plastic or even melts so that the fuel of the reactor at any time is not useful for weapons. Thus, the combination of sealing the reactor as described above, and the isotopic denaturing of the irradiated fuel will additionally increase the proliferation resistance.

There are less than $300 \mathrm{~kg}$ of UO2 in a reactor module. There are less than $15 \mathrm{~kg}$ of U-235 in a module. The Pu content of the spent fuel will be calculated, but may be estimated to be less than $10 \mathrm{~kg}$. Refueling is done in the factory. The fuel elements are confined in the fuel chamber. The FBNR modules are fabricated, fueled, and sealed in the factory under the supervision of the IAEA safeguard program. They are taken to the site and installed in the reactor and the spent fuel chamber will return to its final destination as sealed. The fuel chamber is stored in a passively cooled intermediate storage at the reactor site before going to the final disposal site or to the reprocessing plant or any other future destination. This should assure safeguarding of the nuclear fuel. The reactor core is surrounded by a jacket of downward flowing water, thus there is insufficient neutron leakage for irradiation purposes outside the pressure vessel. The reactor vessel may be cladded by neutron absorbing materials, if necessary, to eliminate the possibility of neutron irradiation to any external nuclear material. Only the fuel chamber is needed to be transported from factory to the site and return. 
In conclusion, the proposed reactor meets the IAEA requirements for nonproliferation. The concept is based on both sealing of the fuel chamber and denaturing of the fuel itself. The sealing of the fuel in the fuel chamber of a long life reactor, permits the control at any time from "cradle to grave" allowing the continuity of knowledge (COK) about the fuel which guarantees an effective control. The isotopic denaturing of the fissile fuel, both in the U-233/Thorium cycle as well as for the classical $\mathrm{Pu}-239 /$ Uranium cycle, would further increase the proliferation resistance as it will require isotope separation technology to produce weapon grade materials. In this way both intrinsic features and extrinsic proliferation resistance measures are provided. The Continuity of Knowledge (COK) and the communication between stakeholders are facilitated due to the nature of the design. The proposed reactor can utilize a variety of fuel cycles and can benefit from a Multilateral Fuel Cycle concept. In conclusion, the FBNR can be considered as a fool-proof reactor against nuclear proliferation that the present world is looking for to be assured of both safety and safeguarding.

\section{No Need for On-Site Refueling}

The reactor's fuel chamber is fuelled in the factory. The international safeguard authorities seal the fuel chamber. The FBNR can have a very long fuel cycle time depending on the projected size of reserve fuel chamber. The core life is decided according to the user's need. No refueling on the site is necessary because the fuel elements are always in the sealed fuel chamber and transported to and from the factory for refueling under surveyed condition. Refueling is done by the replacement of fuel chamber. The length of the fuel cycle chosen depends on the economic analysis of the fuel inventory for particular situation of the reactor and its application. The FBNR fuel elements have high burn up capacity. The size of the reserve fuel chamber can be adapted to individual needs. The replacement of fuel chamber is done at any desired time interval and could be set at every 10 years or for the reactor lifetime.

There is no need for fresh fuel to be stored at the reactor site since the sealed fuel chamber is transported to and from the factory where the refueling process is performed. The spent fuel are confined in the sealed fuel chamber and kept cool by its water tank. It can be sent back to the factory at any time when the radiological requirements are met. No unauthorized access to the fresh or spent fuel is possible because the fuel elements are either in the core or in the fuel chamber under sealed conditions. Therefore, no clandestine diversion of nuclear fuel material is possible.

\section{Some Other Characteristics of FBNR}

- FBNR is simple in design, inherently safe without adverse environmental impact.

- The FBNR is shop fabricated, thus it guarantees the high quality fabrication and economic mass production process.

- FBNR uses a proven technology namely that of the conventional pressurized water reactors (PWR).

- FBNR is small in nature. The optimum size is about 70 MWe. The higher power can be achieved at the cost of a lower thermodynamic efficiency.

- The obvious simplicity of the design and the lack of necessity for complicated control system, make the reactor highly economic. 
- The steam generator is housed within the pressure vessel having an integrated system, thus avoiding the problems associated with a possible steam generator leakage.

- Easy dismantling and transportability.

- The reactor can be operated with a reduced number of operators or even be remotely operated without any operator on site.

- FBNR is an Inherently Safe and Passively Cooled Reactor.

- The FBNR is a nuclear power plant for urban or remote localities.

- The FBNR is designed to produce electricity alone or to operate as a cogeneration plant producing simultaneously: electricity, desalinated water, and steam for industrial purposes and heat for district heating. A Multi- Effect Distillation (MED) plant may be used for water desalination. An estimated $1000 \mathrm{~m} 3 /$ day of potable water could be produced at $0.6 \mathrm{MW}(\mathrm{e})$ reduction of the electric power.

- No Need for On-Site Refueling. The reactor's fuel chamber is fuelled in the factory. The fuel chamber is sealed by the national and international safeguard authorities.

- The FBNR can have a very long fuel cycle time depending on the projected size of reserve fuel chamber and the fuel enrichment. The core life is decided according to the user's need. No refueling on the site is necessary because the fuel elements are always in the sealed fuel chamber and transported to and from the factory for refueling under surveyed condition. Refueling is done by the replacement of fuel chamber. The length of the fuel cycle chosen depends on the economic analysis of the fuel inventory for particular situation of the reactor and its application.

- There is no need for fresh fuel to be stored at the reactor site since the sealed fuel chamber is transported to and from the factory where the refueling process is performed.

- The spent fuel are confined in the sealed fuel chamber and kept cool by its water tank. It can be sent back to the factory at any time when the radiological requirements are met. No unauthorized access to the fresh or spent fuel is possible because the fuel elements are either in the core or in the fuel chamber under sealed condition. Therefore, no clandestine diversion of nuclear fuel material is possible.

- FBNR resists against "Terrorist Action", "Explosion", "Earthquake", "Flooding", "Fire", "Tornado" and "Bombing". Any adverse event disturbs the signals from the multiple detectors that go into the control system. Any abnormal signal outside the range of operation from any of the detectors will signal an accident. In such a case the power is automatically cut off, the pump and the fuel elements will fall out of the reactor core by the force of gravity and become stored safely in the passively cooled fuel chamber.

- Due to its inherent safety and passive cooling characteristics, the FBNR does not have the complicated and expensive control and emergency core cooling systems existing in the conventional reactors.

- It does not need sophisticated containment building.

- It does not need fuel storage on site.

- There is no fuel assembly.

- There is no large expensive pressure vessel. 
- FBNR utilizes the existing well proven Pressurized Water Reactor (PWR) technology. There are various firms that can furnish components of the reactor. The fabrication of the reactor essentially involves assembling the components fabricated elsewhere around the world.

- FBNR can be built in urban area as it is inherently safe and has a reduced environmental impact. Its underground containment building hides its industrial image and makes the nuclear power plant with FBNR an agreeable place to visit and can become a pleasant park or a garden for the city.

- A small developing country can benefit from the development of FBNR. The electricity and desalinated water are the urgent necessities of humanity in general and any developing country in particular. The engagement of a country in the development of FBNR will help advancement of science and technology in that country.

- A small country with no nuclear technology and modest capital can contribute to the development of the FBNR. The bureaucracy and complicated licensing procedures in industrialized countries make deployment of any new reactor concept too slow in those countries. The country can accept the standards set by the IAEA with minimum additional requirements. The industrial countries have developed many new exigencies that have complicated the deployment of new nuclear reactors.

- FBNR is a technically sound project. The principles of FBNR concept are simple and easily can be understood even by lay persons.

- FBNR is economically competitive. Innovation creates a new paradigm. FBNR utilizes the "Economy of Numbers" instead of "Economy of Scale". The FBNR components are shop fabricated with much higher quality than is possible to be done on the site. The simplicity and mass production process will make them very economic.

- FBNR is given the title of "People's reactor" and "Peace Reactor". The title of "People's Reactor" was suggested as it is at disposition of all who are interested in the project. The stakeholders are humanity in general without any restrictions. This is possible as it is a fool proof non-proliferating nuclear reactor. The title "Peace Reactor" was suggested as it can serve as an instrument of peace by "bringing together" the adverse countries around a common high technical project in the interest of establishing harmony and peace. How noble it would be should some of the countries come together in order to develop the FBNR project producing technology, electricity, desalinated water, and above all peace.

\section{Spent Fuel of FBNR Is Nuclear Waste}

The spent fuel from FBNR is in a form and size (15 mm diameter spheres) that can directly be used as a source of radiation for irradiation purposes in agriculture, industry, and medicine. This feature results in a positive impact on waste management and environmental protection. Therefore, the spent fuel from FBNR should not be considered as waste as it can perform useful functions. Should reprocessing not be allowed, the spent fuel elements can easily be vitrified in the fuel chamber and the whole chamber deposited directly in a waste repository. These factors result in reduced adverse environmental impact. 


\section{Acknowledgments}

The author would like to thank the International Atomic Energy Agency (IAEA) for the 3 years financial support (Research Contract No. 12960) to develop the FBNR nuclear reactor concept in its program of Small Reactors Without On-Site Refuelling (SRWOSR). Also to thank to Roque Antonio Santos, for revision and editing of the manuscripts of this paper.

\section{Conflict of Interest}

The authors declare no conflict of interest

\section{References and Notes}

1. Rio+20: The United Nations Conference on Sustainable Development Homepage. Available online: http://www.rio20.gov.br/ (accessed on 30 July 2012).

2. Sustaining Societies: Towards a New 'We'; Bahá'í International Community: Haifa, Israel, 2012. Available online: http://www.bic.org/statements/sustaining-societies-towards-new-we (accessed on 02 July 2012)

3. Rethinking Prosperity: Forging Alternatives to a Culture of Consumerism; Bahá'í International Community: Haifa, Israel, 2010. Available online: http:/www.bic.org/statements/rethinkingprosperity-forging-alternatives-culture-consumerism (accessed on 2 July 2012).

4. Hatcher, W.S. The Concept of Spirituality; Association for Bahá'í Studies: Ottawa, Canada, 1982; Volume 11.

5. Our Global Neighborhood; The Report of the Commission on Global Governance; Oxford University Press: Oxford, UK, 1995; ISBN 0-19-827998-1.

6. FBNR. Nuclear Reactor for Developing Countries; Fixed Bed Nuclear Reactor: Porto Alegre, Brazil, 2010. Available online: http://www.sefidvash.net/publications/FBNR_power\%20point\% 2001\%2002\%2010.pdf (accessed on 2 July 2012)

7. Sefidvash, F. Desalination by fluidized bed nuclear reactors. Kerntechnik 1999, 64, 1-5. Available online: http://www.sefidvash.net/publications/103\%29Water\%20Desalination\%20By\% 20FLuidized\%20Bed\%20NUclear.pdf (accessed on 2 July 2012).

8. INPRO Homepage. Available online: http://www.iaea.org/inpro (accessed on 30 July 2012).

9. Sefidvash, F. Fixed Bed Nuclear Reactor Concept. In Proceedings of the International Conference on Innovative Technologies for Nuclear Fuel Cycles and Nuclear Power, Vienna, Austria, 23-26 June 2003; IAEA-CN-108/3P.

10. Sefidvash, F. Fixed Bed Nuclear Reactor Concept. Innovative Small and Medium Sized Reactors: Design Features, Safety Approaches and R\&D Trends; IAEA-TECDOC-1451. 2005; pp. 193-202.

11. Sefidvash, F. Fixed Bed Suspended Core Nuclear Reactor Concept. In Proceedings of the International Conference on Innovative Technologies for Nuclear Fuel Cycles and Nuclear Power, Vienna, Austria, 23-26 June 2003; pp. 463-465.

12. Status of Small Reactor Designs without On-site Refuelling; International Atomic Energy Agency: Vienna, Austria, 2007; IAEA-TECODC-1536.

13. FBNR Homepage. Available online: http://www.sefidvash.net/fbnr (accessed on 30 July 2012). 
14. Sefidvash, F. Preliminary Neutronics Calculations of the Fixed Bed Nuclear Reactor-FBNR, Status of Small Reactor Designs without On-site Refuelling (CD-ROM); 2007; IAEA-TECDOC-1536.

15. Sefidvash, F. Thermal hydraulics of the fixed bed nuclear reactor concept. Kerntechnik 2006, 71, $1-5$.

16. Sefidvash, F. Fixed bed suspended core nuclear reactor concept. Kerntechnik 2003, 68, 56-59.

17. International Atomic Energy Agency. Milestones in the Development of a National Infrastructure for Nuclear Power; IAEA: Vienna, Austria, 2007; Nuclear Energy Series No. NG-G-3.1.

18. Guidance for the Application of the Assessment Methodology for Innovative Nuclear Energy Systems -INPRO Manual: Overview of the Methodology; International Atomic Energy Agency: Vienna, Austria, 2008; IAEA-TECDOC-1575; Volumes 5-6.

19. Sefidvash, F.; Seifritz, W. A fool proof non-proliferation nuclear reactor concept. Kerntechnik 2005, 70, 243-245.

20. Sefidvash, F. Preliminary Evaluation of the Fixed Bed Nuclear Reactor Concept Using IAEA-INPRO Methodology. In Proceedings of the 12th International Conference of Nuclear Engineering, Arlington, VA, USA, 25-29 April 2004.

21. Sefidvash, F. Preliminary evaluation of the fixed and fluidized bed nuclear reactor concept using the IAEA-INPRO methodology. Kerntechnik 2004, 69, 1-6.

22. Guidance for the Evaluation of Innovative Nuclear Reactors and Fuel Cycles; International Atomic Energy Agency: Vienna, Austria, 2003; IAEA-TECDOC-1362.

(C) 2012 by the authors; licensee MDPI, Basel, Switzerland. This article is an open access article distributed under the terms and conditions of the Creative Commons Attribution license (http://creativecommons.org/licenses/by/3.0/). 